\title{
Applying a ground support and reinforcement design methodology
}

\author{
D. Finn Newcrest Mining Ltd, Australia
}

\begin{abstract}
Utilising a ground support design methodology is an important part of designing ground support. This paper describes the application of the ground support and reinforcement design methodology outlined in Kaiser et al. (1996) at Ridgeway Deeps Block Cave. It sets out to describe the benefits of following a methodology, provides a broad format for ground support and reinforcement design, and the steps undertaken to apply the methodology at Ridgeway Deeps.

At the time when ground support was being designed the Ridgeway Mine was in the process of transitioning from sublevel cave to block cave mining. This brought new challenges and it was anticipated that there would be significantly more deformation and seismic activity because of the increased depth and the mining method being used.
\end{abstract}

The ground support design and implementation had to be able to cater for these conditions and it had to ensure that the mine achieved its development and production targets.

\section{$1 \quad$ Introduction}

Ground support and reinforcement design for underground mines needs to follow a systematic and logical methodology. The site geotechnical engineers need to be able to clearly articulate why the system being utilised is appropriate and optimal for the known conditions, describe how the final ground support and reinforcement system was derived, the changes and adaptations that have occurred and how the design was implemented. This paper seeks to firstly define the key elements required to achieve a systematic ground support design and then demonstrate how these were applied when designing ground support for the Ridgeway Deeps (RWD) Block Cave (BC) Extraction Level (EL).

\section{$2 \quad$ Background}

The Ridgeway Deeps mine is located approximately $250 \mathrm{~km}$ west of Sydney, Australia. The operation is located $3 \mathrm{~km}$ to the north west of the Cadia Hill open cut gold mine, and approximately $25 \mathrm{~km}$ south of Orange, New South Wales (Figure 1). Ridgeway Deeps, Ridgeway, Cadia East, and Cadia Hill gold mines form Cadia Valley Operations, which is owned and operated by Newcrest Mining Ltd. The Ridgeway gold-copper orebody was discovered in November 1996, with initial mining commencing in March 2002 using the sublevel caving method (SLC). A production transition from the Ridgeway SLC to RWD block cave occurred in 2010. The RWD block cave (BC) is located approximately $210 \mathrm{~m}$ below the existing Ridgeway SLC and $1,100 \mathrm{~m}$ below ground surface. The expected remaining mine life is five years (2017) based on current reserves. Production is expected to be $1.2 \mathrm{Moz}$ of gold and $0.17 \mathrm{Mt}$ copper, with an annual mining rate of $6 \mathrm{Mt}$ (Newcrest, 2011). 

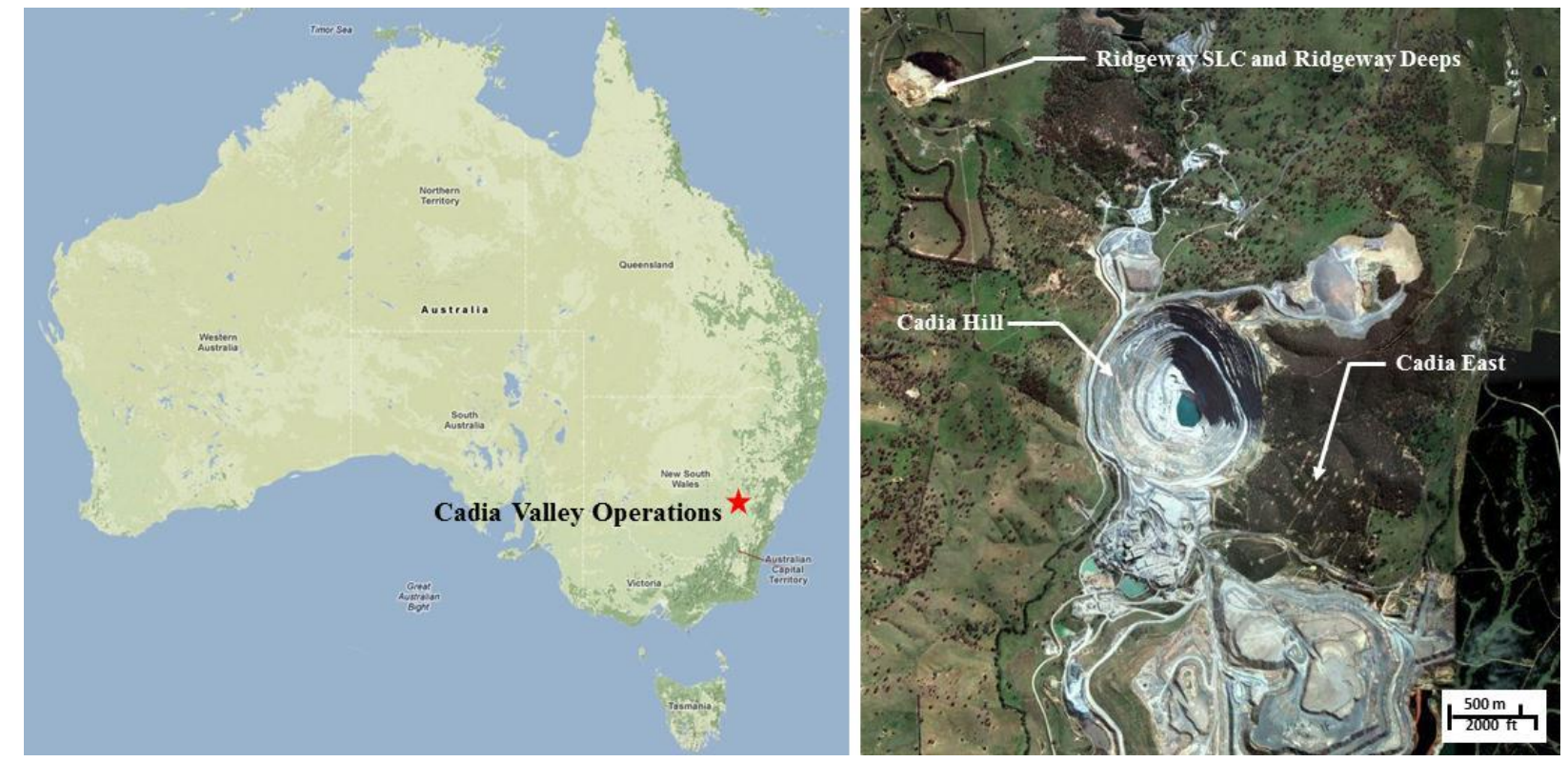

Figure 1 Location of Cadia Valley Operations and Ridgeway, Cadia Hill and Cadia East

\section{Situation}

The Ridgeway SLC was successfully mined with ground support systems utilising fully grouted resin bolts, fibre-reinforced shotcrete (FRS) and cable bolting of intersections with single strand fully grouted cable bolts. However, the results of numerical modelling predicted, and early development confirmed, that the mining conditions would be significantly different between the SLC and the BC, and upgrades in the support systems would be required when mining the BC. The main purpose of these upgrades was to accommodate the likely deformations and the potential impact of seismicity on excavation stability.

Once the caving process commences there is a rapid change to mining conditions. At RWD this involved the breakup of over 40 million $t$ of rock over a period of about 18 months and resulted in significant redistribution of the stress field. As a result, the site specific customisations often applied to mines where the initial ground support system evolves with experience, observations and the gradual change in mining conditions could not be applied at RWD.

A robust design methodology was required to cater for the expected conditions and the rapid changes that would occur once caving commenced. It had to have the capacity to deal with a significantly increased depth of failure, increased deformation and dynamic loading from seismic events in and around the cave.

\section{$4 \quad$ Essentials}

To achieve the optimum ground support and reinforcement for excavations the design engineer must:

1. Understand the functional requirements of the excavations to be supported.

2. Define the geological and geotechnical environment where the excavations are to be mined.

3. Define the support and reinforcement system demand.

4. Define the support and reinforcement capacity.

5. Monitor the performance of the installed ground support system.

The ground support design process should follow a clear and documented methodology. This should reflect industry leading practice and follow systematic and practical design logic and ideally it should withstand the rigors of peer review and application elsewhere. The results should be documented so that others can assess and track the work. 


\section{$5 \quad$ Function of the extraction level drives}

RWD BC consists of an extraction level (4786 Level) and an undercut level (4804 Level) $18 \mathrm{~m}$ above the extraction level. The general design of these levels and associated drawbells is shown in Figures 2 and 3. The block cave was established using an advanced undercut crinkle cut design. Total undercutting area was approximately $85,000 \mathrm{~m}^{2}$ (approximate maximum dimensions $490 \times 180 \mathrm{~m}$ ), and was commenced in the north east footprint corner and retreated to the south west. The extraction level was developed to an offset herring bone layout and the dimensions are shown in Figure 2. A total of 248 drawpoints were developed, with production from all drawpoints occurring by November 2010. Material handling to surface is achieved through two underground jaw crushers, and conveyor belt system to surface.

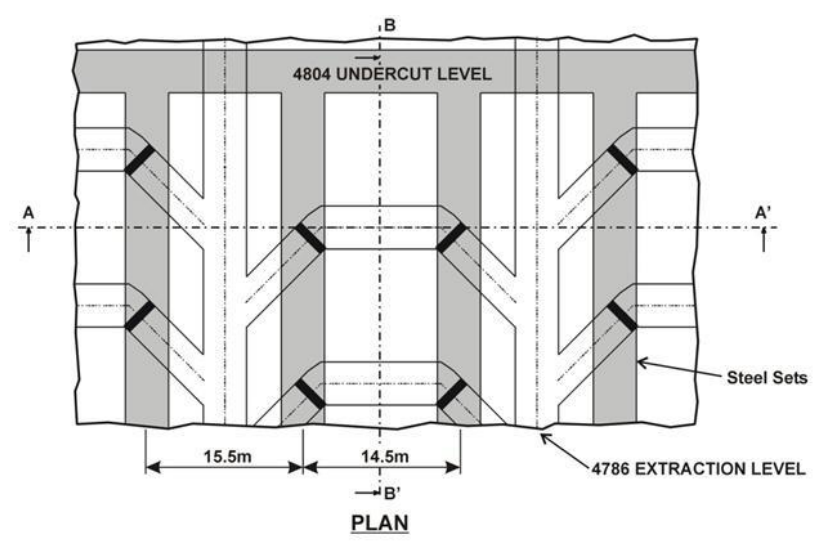

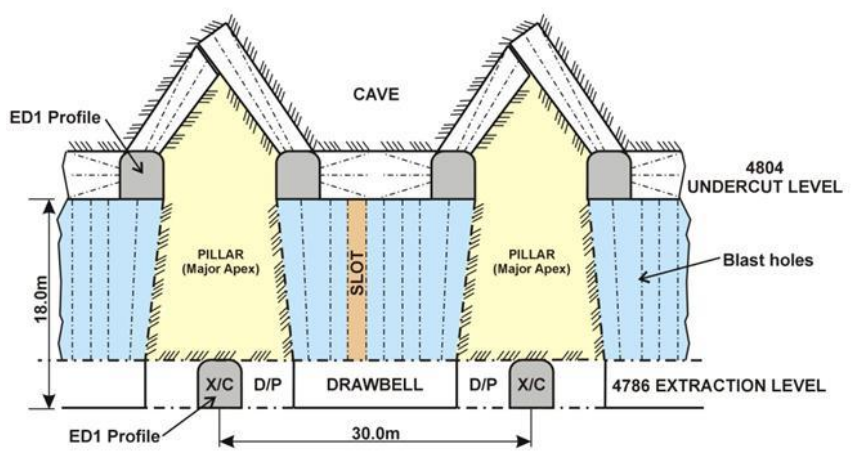

A. Section Across the Major Apex

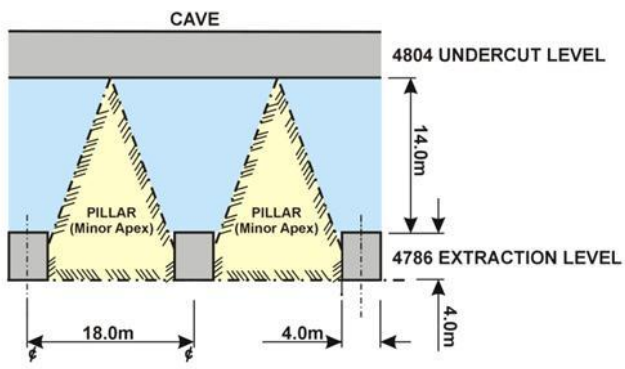

B. Section Across the Minor Apex

Figure 2 The geometry and layout of the EL

On the extraction level there are essentially five excavation types and their functions are:

- Excavations to house the crushers and associated equipment.

- Perimeter drives that provide the ventilation flow and connect the ore drives to the crusher tipples.

- EL drives.

- Draw points which break off the EL drives and are the extraction points for ore from the BC.

- And the draw bell development, a sacrificial drive that forms the bottom of the draw bell.

This paper only covers the design of the ground support and reinforcement of the EL drives. The purpose of these drives is to tram ore using production loaders between the draw points and the crushers, enabling the mine to safely produce at its design capacity of $6 \mathrm{Mtpa}$ for life of mine. 


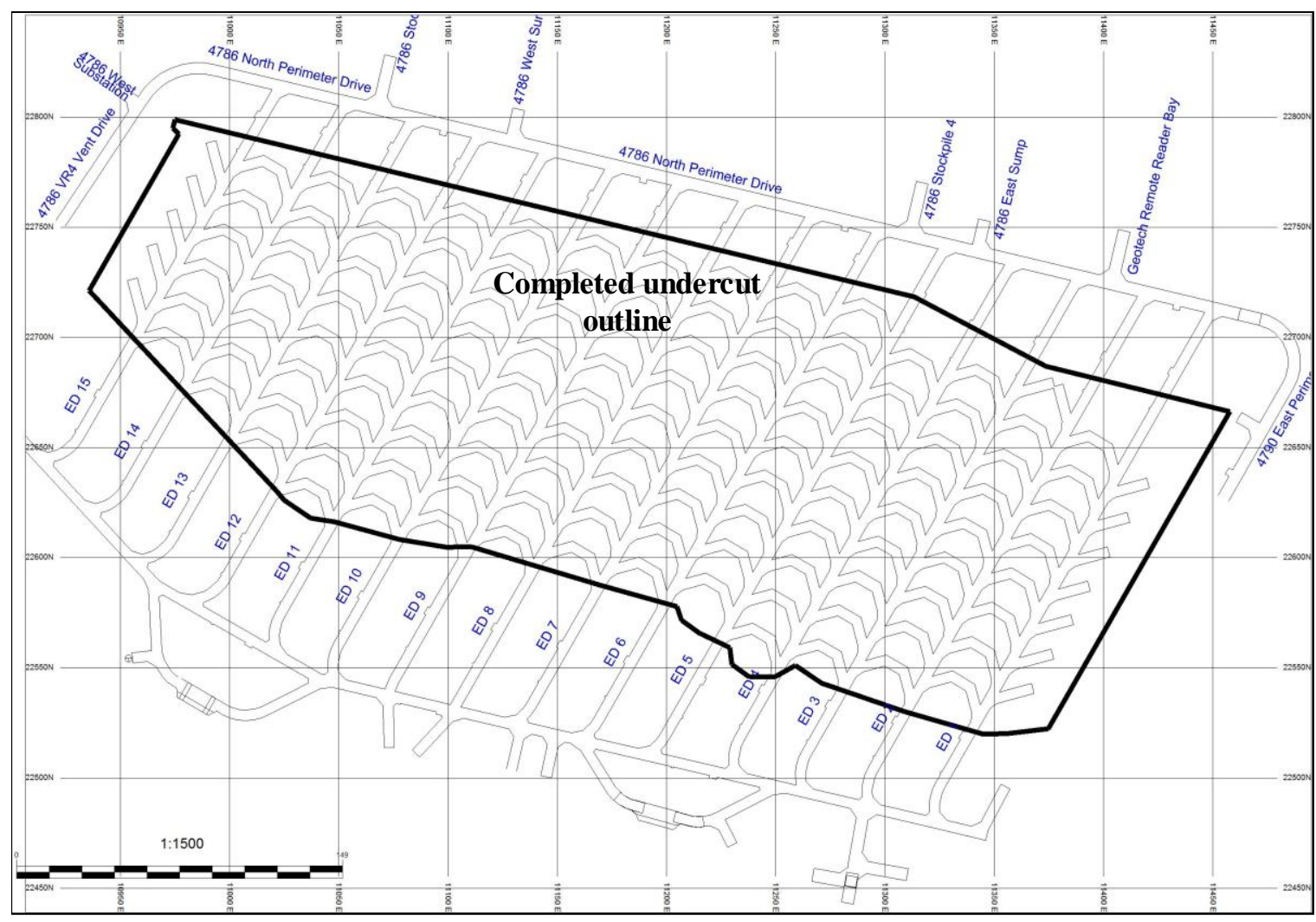

Figure 3 Plan of the Ridgeway Deeps EL

\section{Defining the geology and geotechnical environment}

\subsection{Geology overview}

The Ridgeway deposit is a structurally controlled gold-copper porphyry orebody characterised by stockwork and sheeted quartz veins containing copper sulphides (Smart and O'Sullivan, 2006). The deposit is centred on a subvertical monzonite stock of the Late Ordovician to Early Silurian. The orebody is contained within the Forest Reef Volcanics and sediments of the Weemalla Formation, and has a maximum dimension of approximately $400 \mathrm{~m}$ east-west, $250 \mathrm{~m}$ north-south, and in excess of $1,000 \mathrm{~m}$ vertically (Smart and O'Sullivan, 2006). Mineralisation extends over 1,000 m in vertical extent, from $500 \mathrm{~m}$ below the surface and is open at depth.

\subsection{RWD geotechnical model}

To quantify and readily represent the ground conditions at RWD a geotechnical model was developed. This collated geological and geotechnical data into one model allowing the ground conditions to be quantified and presented for mining assessments. The geology team (Ferguson, 2009) provided interpretations of the lithology, alteration, microfracturing, mineralisation, major structures and secondary scale structures from core logging and underground mapping. The geotechnical team collected data on structural orientations, joint set numbers, planarity and infill characteristics (Lett, 2009a). A hydrogeology assessment of the orebody was completed by Hall (2006) and the results of testing completed during the hydrofracturing trials Jeffrey (2007) were also assessed. Intact rock testing of drill core was completed and compiled by Lett (2009b).

This allowed Lett (2009a) to divide the rock mass into geotechnical domains and assess the rock mass properties within each domain. The model was not completed exclusively for stability or ground support selection and the model represents the BC from below the EL at $4786 \mathrm{RL}$ to the base of the SLC at $5010 \mathrm{RL}$. 
The geotechnical domains encountered on the EL, their typical $Q^{\prime}$ and intact rock properties are shown in Table 1 and Figure 4 shows the location of the rock mass domains on the EL.

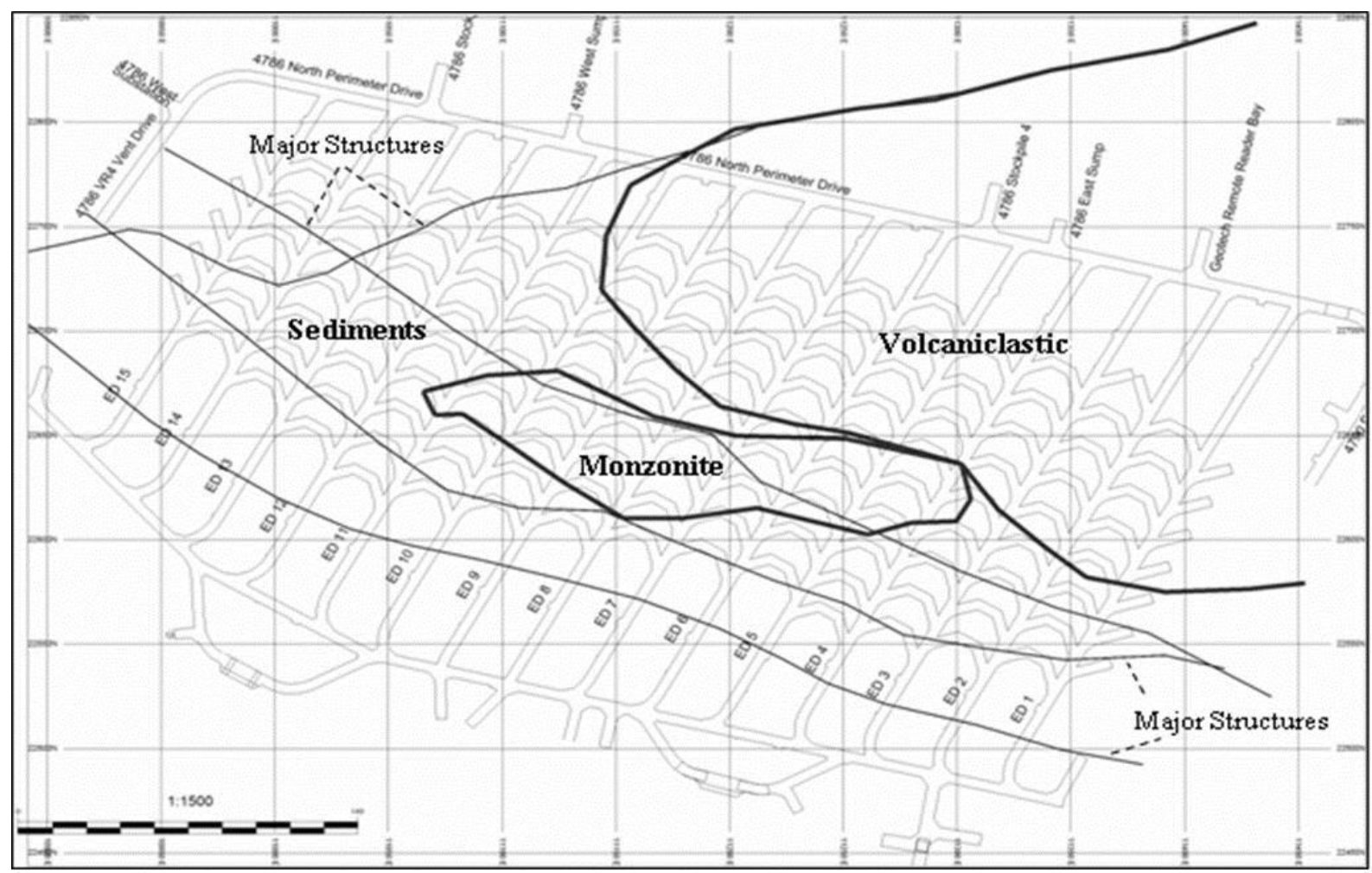

Figure 4 The geotechnical domains on the EL

Table 1 Rock mass $Q$ prime ratings and intact rock properties (after Lett, 2009b)

\begin{tabular}{lccccccc}
\hline & \multicolumn{3}{c}{ Statistical Results Q Prime } & \multicolumn{3}{c}{ Intact Rock Properties Mean Values } \\
$\begin{array}{l}\text { Extraction Level } \\
\text { Domain }\end{array}$ & $\begin{array}{l}\text { Lower } \\
\text { Quartile }\end{array}$ & Mean & $\begin{array}{c}\text { Upper } \\
\text { Quartile }\end{array}$ & Median & UCS (MPa) & E (GPa) & v \\
\hline Sediments & 1.3 & 5.9 & 8.2 & 4 & 99 & 70 & 0.25 \\
Volcaniclastics & 4.9 & 12.8 & 16.7 & 9 & 116 & 68 & 0.27 \\
Monzonite & 11.9 & 23.9 & 25 & 22 & 121 & 68 & 0.26 \\
Porphyry & 8.3 & 12.9 & 15.7 & 15.1 & 126 & 68 & 0.30 \\
North Fault Zone & 2.8 & 6.4 & 8.3 & 4.8 & Not tested & Not tested & Not tested \\
Purple Fault Zone & 1.2 & 5.8 & 8.1 & 3.8 & Not tested & Not tested & Not tested \\
Claudia Fault Zone & 0.3 & 6.1 & 8.8 & 2.2 & Not tested & Not tested & Not tested \\
\hline
\end{tabular}

The rock mass modelling was done in Datamine Studio 3 using the block modelling routines available within that package and care was taken to domain up the orebody ensuring that major fault domains included the area around the faults where the ground conditions have been affected by the fault. Blocks within the model were populated by using a nearest neighbour interpolation technique. As noted by Lett (2009a), the model does not delineate the exact ground conditions at a specific location but provides a guide to the values that will be encountered within the domain. Figure 5 shows the zoning of the $Q$ prime values for the EL. 


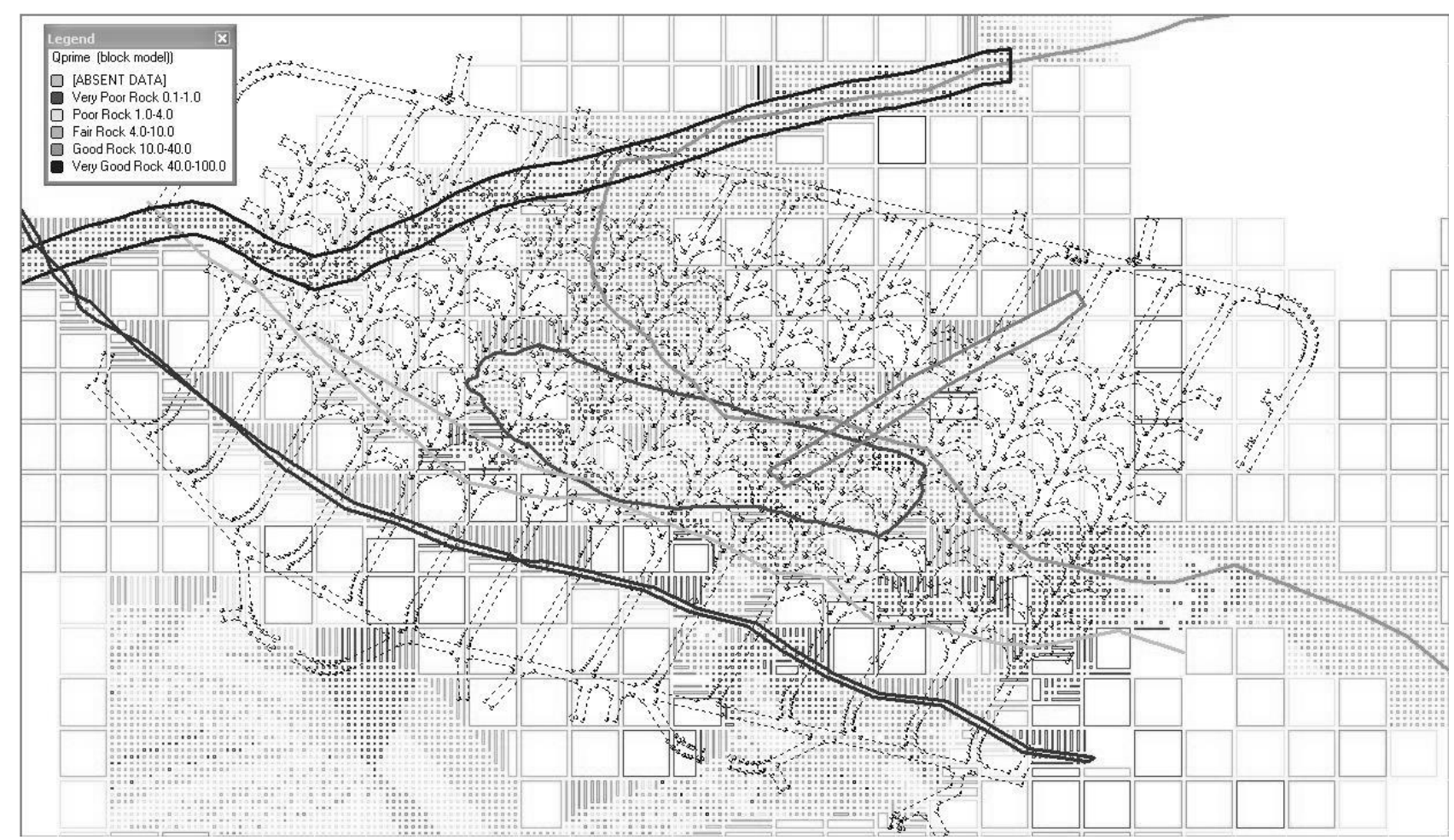

Figure 5 Geotechnical model of $\mathrm{Q}$ prime zones on the EL

\subsection{In situ stress}

RW mine has completed 24 individual stress measurements at various levels through the mine. These, together with the back-analysis of damage to the excavations, have provided a high degree of confidence in the orientations and magnitude of the in situ stress field. The in situ stress field used for numerical modelling is summarised in Table 2.

Table 2 Pre-Mining Stress at depth below surface of 1,100 m (4786 RL)

\begin{tabular}{cccc}
\hline & Magnitude (MPa) & Dip & Dip Direction \\
\hline$\sigma_{1}$ & 65 & $5^{\circ}$ & $240^{\circ}$ \\
$\sigma_{2}$ & 47 & $68^{\circ}$ & $138^{\circ}$ \\
$\sigma_{3}$ & 32 & $22^{\circ}$ & $332^{\circ}$ \\
\hline
\end{tabular}

The dip direction is relative to local mine grid which is orientated at $32^{\circ}$ to AGM Grid North.

\section{$7 \quad$ Numerical modelling}

Several phases of numerical modelling were completed using Map3D ${ }^{\mathrm{TM}}$, Abaqus ${ }^{\mathrm{TM}}$ and FLAC3D ${ }^{\mathrm{TM}}$. The numerical modelling commenced during prefeasibility and continued through feasibility and implementation and is now being used during the operational phase of the mine. These later models incorporated the results of the geotechnical model and the latest geology models. The models were continually refined by building on the learning of previous models and calibrating the models to the results of geotechnical monitoring, Lett and Capes (2012) and damage mapping which is illustrated in Figure 6 . The modelling has culminated in the use of interactively coupled modelling that used Abaqus ${ }^{\mathrm{TM}}$ to model the growth of the cave and CaveSim to model the flow of material within the cave, Beck et al. (2011) and Sharrock et al. (2012). This provides the most realistic prediction of cave growth shapes at each stage of the cave propagation and therefore indications of where and when damage will occur on the extraction level. 


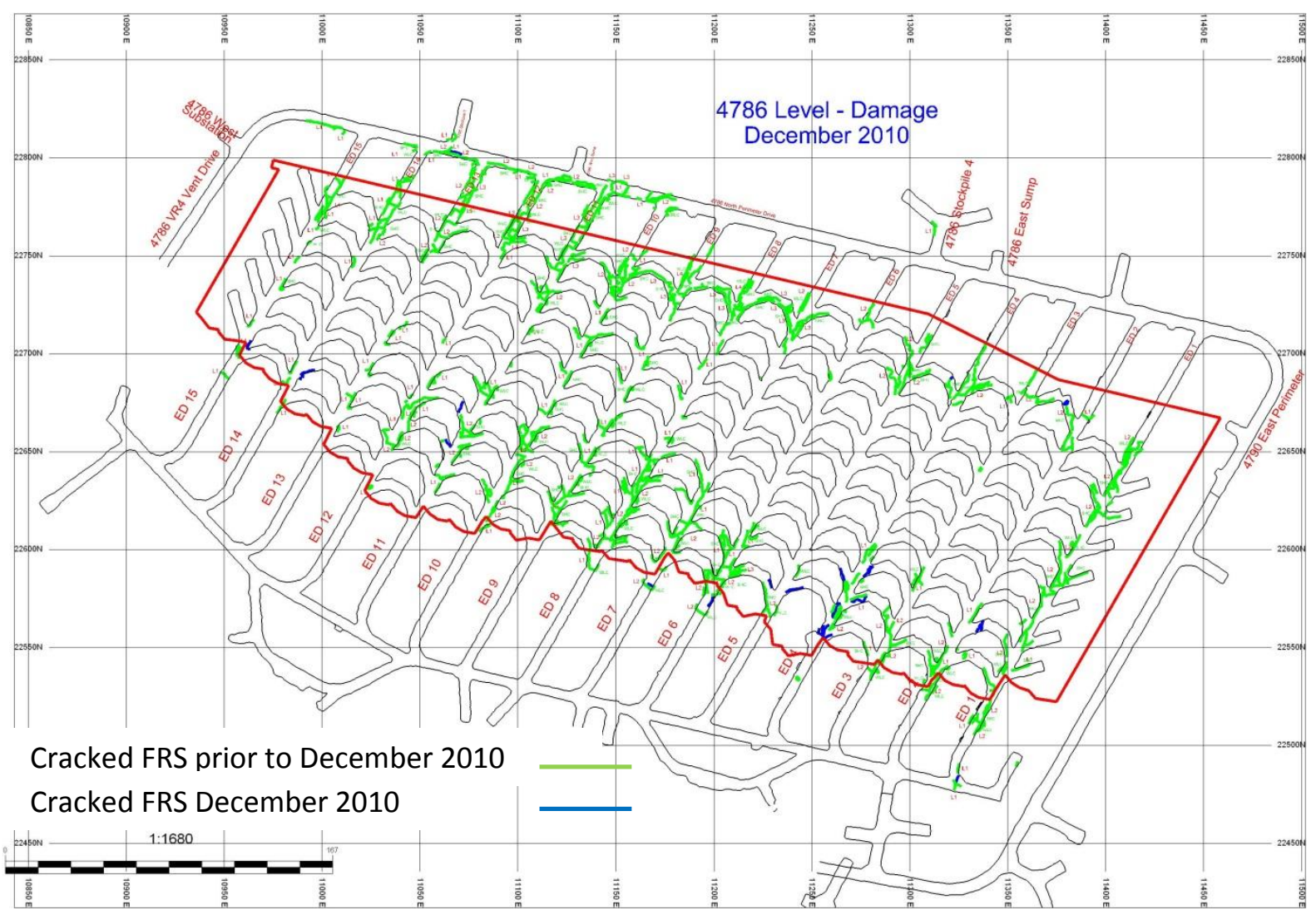

Figure 6 Damage mapping of the $4786 \mathrm{EL}$

Numerical modelling was undertaken to assess several aspects of the $B C$ such as cave growth, subsidence and the timing of the BC breakthrough into the SLC. One important output is an assessment of stress and plastic strain, with plastic strain being used as a measure of damage. The magnitude of damage on mine development and the timing of when this damage is likely to occur were estimated using plots such as Figure 7. 


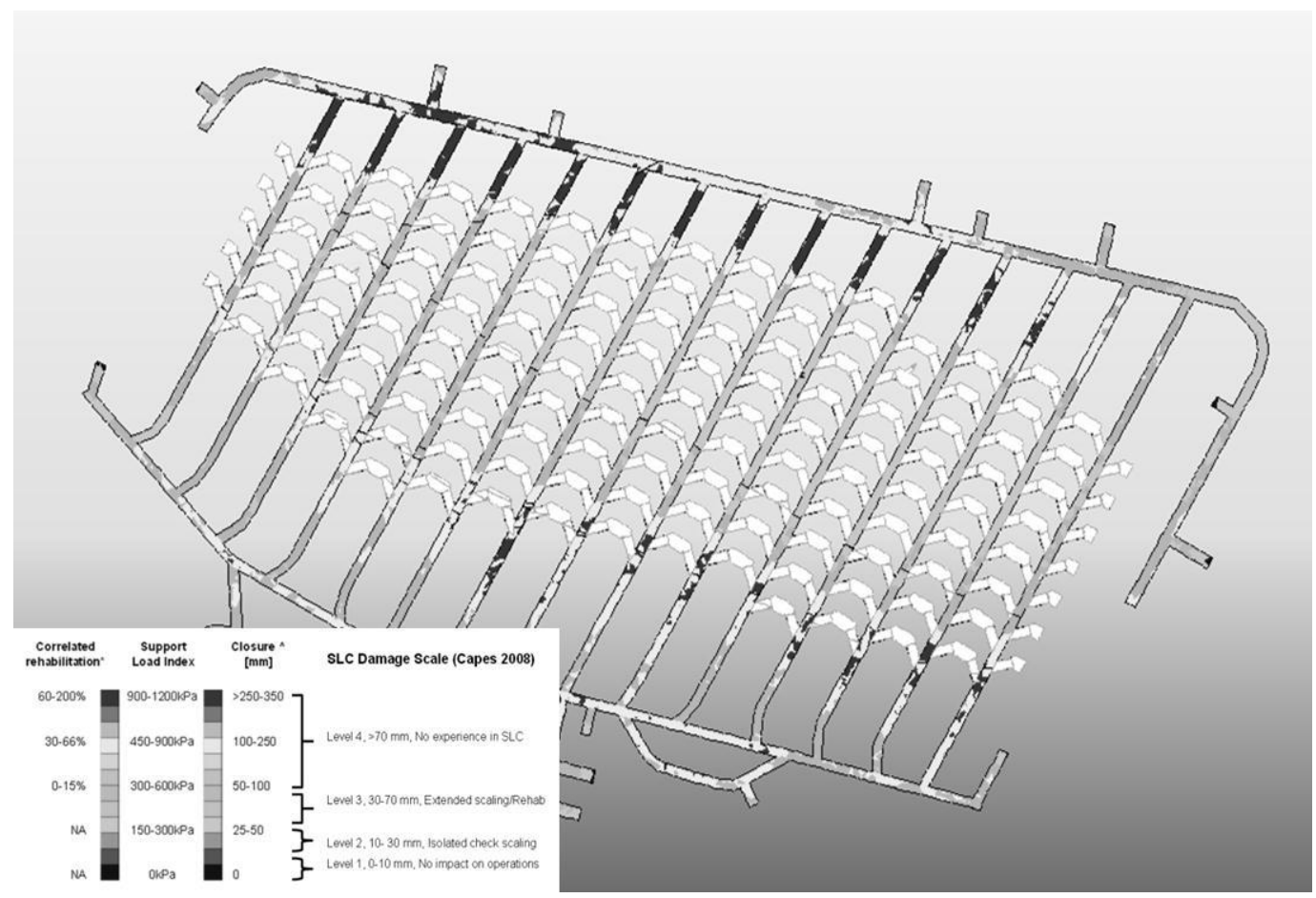

Figure 7 Results of numerical modelling showing support load estimates for the EL (after Beck Arndt Engineering, 2009; and Sharrock, 2009)

\section{$8 \quad$ Monitoring}

RWD was extensively monitored from the outset of mining Finn (2007) and Lett and Capes (2012). The monitoring consisted of open holes, extensometers, closure pins and an IMS seismic system. The seismic system was installed in the mine prior to caving commencing, and consisted of an array of 24 accelerometers which were arranged around the volume to be caved and 6 low frequency geophones set further away from the cave. The intent of the geophones was to register and record any very large events that had the potential to saturate the closer accelerometers. To ensure that the mine would have sensor coverage on all sides of the cave volume, a purpose built monitoring drive was mined at the 5010 Level which extended to the east of and to the north of the BC. This drive along with the 5100 Level hydro-fracture drive which was placed directly over the eastern side of the cave resulted in a seismic array which was capable of recording the magnitude and position of seismic events accurately, Lett and Capes (2012).

\section{$9 \quad$ Likely failure modes}

The likely behaviour of the rock mass on the EL at RWD, and the likely failure modes were assessed using the experiences gained mining the RW SLC, reviewing the geotechnical model, reviewing the results of numerical modelling, reviewing the available literature Brown (2003) and by using experience, benchmarking of other mines and engineering judgement.

From this work several potential failure modes were identified for the RWD EL:

- Structurally controlled wedge failures.

- Unravelling failures where the rock mass is broken or altered to a clay close to fault zones.

- Stress fracturing during development.

- Stress fracturing due to mining-induced loads.

- Mining-induced deformation. 
- Strainbursts during development.

- Shakedown due to remote fault slip generated seismic events.

Each would have to be assessed and the final ground support design would have to ensure that each potential failure mechanism could be managed and that the EL could perform its design function.

\section{Quantifying system demand}

To assess the support and demand from these potential failures they can be divided broadly into static and dynamic loading.

\section{$10.1 \quad$ Static loading}

\subsubsection{Mining deformation}

RWD was developed in a relatively strong rock mass in high stress conditions, so stress fracturing around the excavation and loading of EL pillars were expected. The combined effects of the dilation due to stress fracturing and pillar loading were expected to result in significant deformations of the EL development. Due to the complex geometries and complex loading histories, numerical modelling was the only viable way of assessing the location, magnitude and timing of the deformation and damage over the life of the mine. The results of some of the numerical modelling completed for RWD EL are depicted in Figure 7, showing high deformations at the abutments of the EL which reduce at the centre of the EL. The modelling allowed the EL to be broken into two broad zones; a moderate deformation area in the centre of the footprint where closures of between 25 to $75 \mathrm{~mm}$ were anticipated, and a high deformation area where closures of 100 to $250 \mathrm{~mm}$ of deformation were anticipated.

At the time of the design in 2009, closures of between 40 to $80 \mathrm{~mm}$ had been recorded on the northern abutment which calibrated well with the modelling at the time. At that time depths of damage between 0.3 to $1.0 \mathrm{~m}$ were recorded in the wall of the EL and between 0.3 to $2.0 \mathrm{~m}$ in the backs. This data was from observations of development breakoffs, monitoring holes and debris in friction bolts.

\subsubsection{Structurally controlled wedge failures}

The results of line mapping and drill core logging of each domain were used to define the main structural sets in each domain. These were assessed in UNWEDGE ${ }^{\mathrm{TM}}$ to define the possible wedges that could form on the EL. No restrictions were imposed on the length of structures forming the wedges so that the maximum size wedges were allowed but engineering judgement was used to assess and exclude wedges that were small $(<1 \mathrm{t})$ or were very steep sided and unlikely to release. The demand of the resulting wedges was assessed against the designed ground support system in UNWEDGE ${ }^{\mathrm{TM}}$.

\subsubsection{Zone of loosening}

A zone of loosening was estimated for static loading conditions by inscribing a parabola with a height of one third the opening width onto the drive cross-section. The volume defined was multiplied by a density of $28 \mathrm{kN} / \mathrm{m}^{3}$ to estimate the static demand on the designed ground support systems.

\subsection{Dynamic loading}

To assess the dynamic demand and the ground support capacity the methodology outlined in Kaiser et al. (1996) and Fuller (2010) was applied by Coffey Mining Pty Ltd (2008) and Sharrock (2009) at RWD, this involved:

- Assessing the maximum event magnitude.

- Assessing the possible location of this event relative to the EL.

- Estimating the peak particle velocity (ppv) at the EL resulting from the design event. 
- Assessing the potential for damaging events on the EL.

- Classifying the likely rockburst damage.

\subsubsection{Maximum event magnitude and event location}

The maximum event magnitude was assessed using a Gutenberg-Richter (GR) frequency magnitude plot, Gutenberg and Richter (1956). Figure 8 shows the GR relation for all events up to June 2009 when the ground support design work was completed. This plot and the linear regression line show that the maximum event was anticipated to be 2.5 local magnitude $\left(\mathrm{M}_{\mathrm{L}}\right)$.

Several events greater than $0.0 \mathrm{M}_{\mathrm{L}}$ and up to $2.2 \mathrm{M} \mathrm{L}$ had occurred to that date at between 19 and $80 \mathrm{~m}$ beneath the EL. The locations of these events were correlated with the Claudia Fault which is a shallow dipping thrust fault under the EL.

At the time of designing the support only one event had resulted in damage to the EL. This occurred on 4 April 2009, $19 \mathrm{~m}$ from the extraction level and was a $1.3 \mathrm{ML}$ event. It resulted in minor damage to the shotcrete shown in Figure 9. The ppv for this event was estimated to be between 0.14 and $0.39 \mathrm{~m} / \mathrm{s}$ at the shortest source to excavation distance.

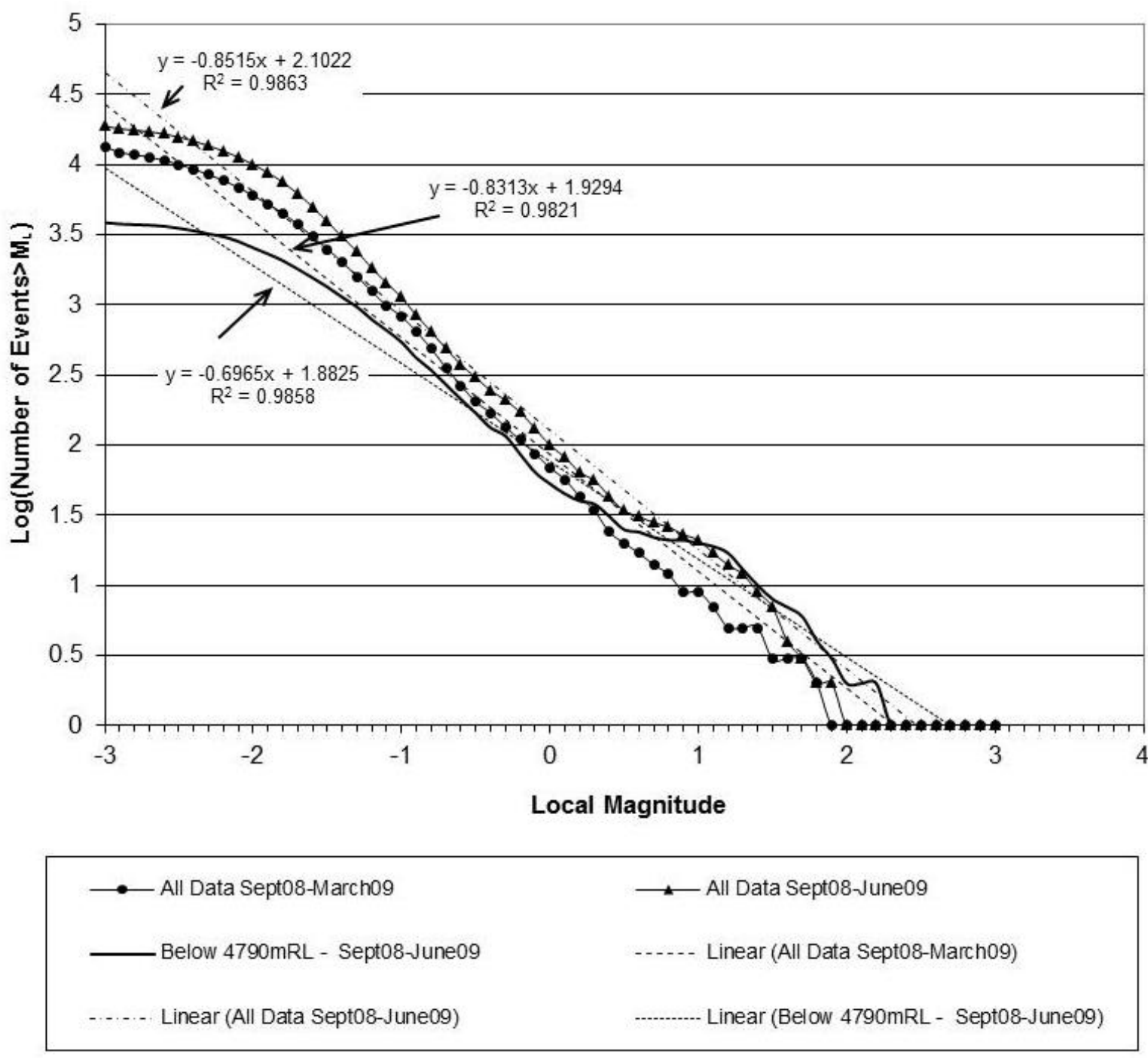

Figure 8 Gutenberg-Richter frequency magnitude plots for RWD seismic data 


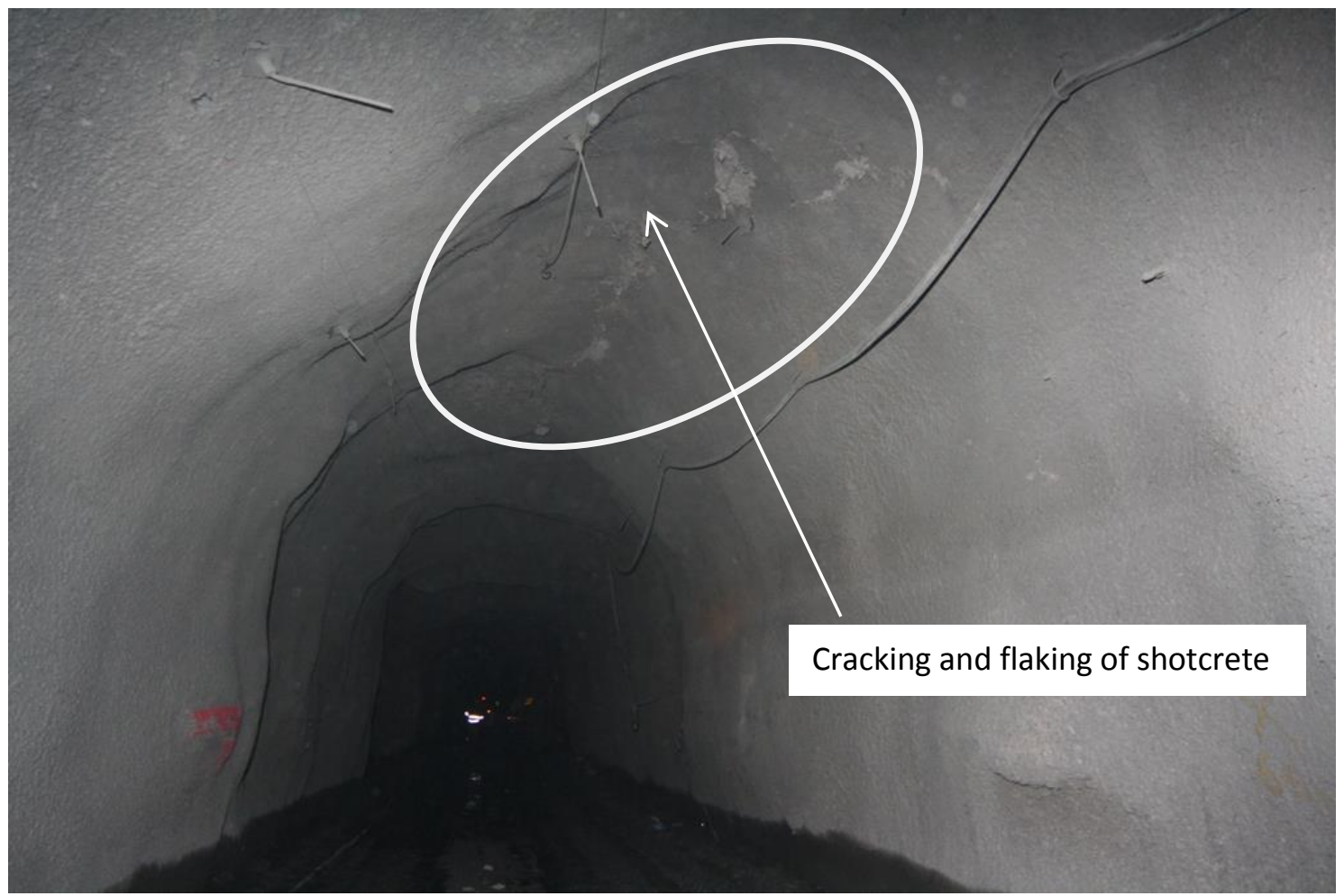

Figure 9 Minor damage of extraction drive 1 following a $1.3 M_{L}$ event

The use of the GR frequency magnitude plot is well established in seismology for predicting the maximum size earthquakes but its limitations need to be kept in mind when applied to cave mines. It is a retrospective analysis, it does not account for source mechanisms or the rapid change of mine geometry associated with caving millions of tonnes of rock. The caving process and the failure of a large crown pillar between the BC and SLC at RWD resulted in significant stress redistribution around the mine which could have a significant effect on source mechanisms of mine seismicity.

\subsubsection{Determining the ground motion}

To assess the demand on the excavation resulting from a seismic event at a distance greater than one to two times the event source radius, ppv at the source must be reduced to account for the energy lost during its travel.

The methodology for estimated ppv at the excavation surface is outlined in Kaiser et al. (1996). ppv far field is defined by Equation 1.

$$
p p v_{\text {far field }}=C^{*}\left(M_{o}^{a}\right) /_{R}
$$

Where:

$R=$ the distance of the excavation from the source.

$C^{*} \quad=\quad$ a site parameter $\left(\mathrm{m}^{2} / \mathrm{s}^{2}\right)$.

$a=$ a site parameter assumed to be 0.5 .

Mo = the seismic moment (GN.m).

To define the parameter $C^{*}$, RWD data was plotted in $\log \left(M_{0}\right)$ and $\log (p p v . R)$ space, as shown in Figure 10. A linear fit with a $95 \%$ confidence interval was used to calculate the $C^{*}$ value which is the intercept of the line with the log (ppv.R) axis when Log $\left(M_{0}\right)$ is equal to zero. Kaiser et al. (1996) recommend that a conservative approach be taken to estimate ground motion values because of the non-uniform radiation of seismic energy at the source, and the effects of local geology and geometry both reduce and enhance the 
energy at the target. Designs therefore used the upper values; in this case a 95\% confidence interval as opposed to the average values.

Log ppv.R versus Log Mo Plot

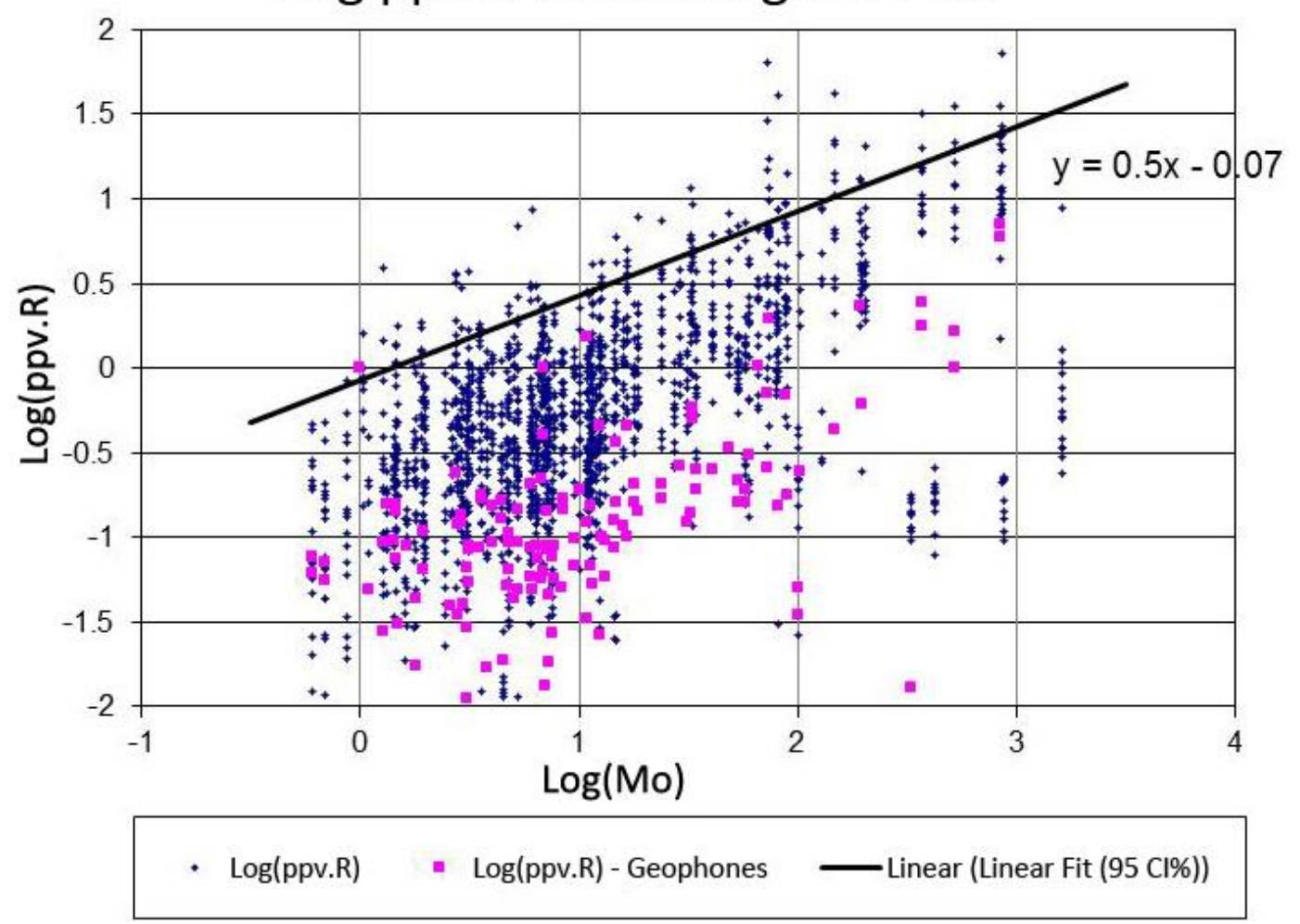

Figure $10 \log \left(M_{\circ}\right)$ and Log (ppv.R) plot for RWD data

$C^{*}$ values were calculated for accelerometers and geophones in the RWD array and were estimated to be 0.85 and 0.30 respectively, with the geophone data being calculated to a $99 \%$ confidence interval.

To apply Equation 1 for RWD a relationship between moment magnitude $\left(M_{0}\right)$ and local magnitude $\left(M_{L}\right)$ for RWD had to be established. A plot of Moment Magnitude and Local Magnitude is shown in Figure 11 and the linear relationship shown in Equation 2 was established.

$$
M_{\circ}=10^{(1.4 \mathrm{ML}+0.352)}
$$




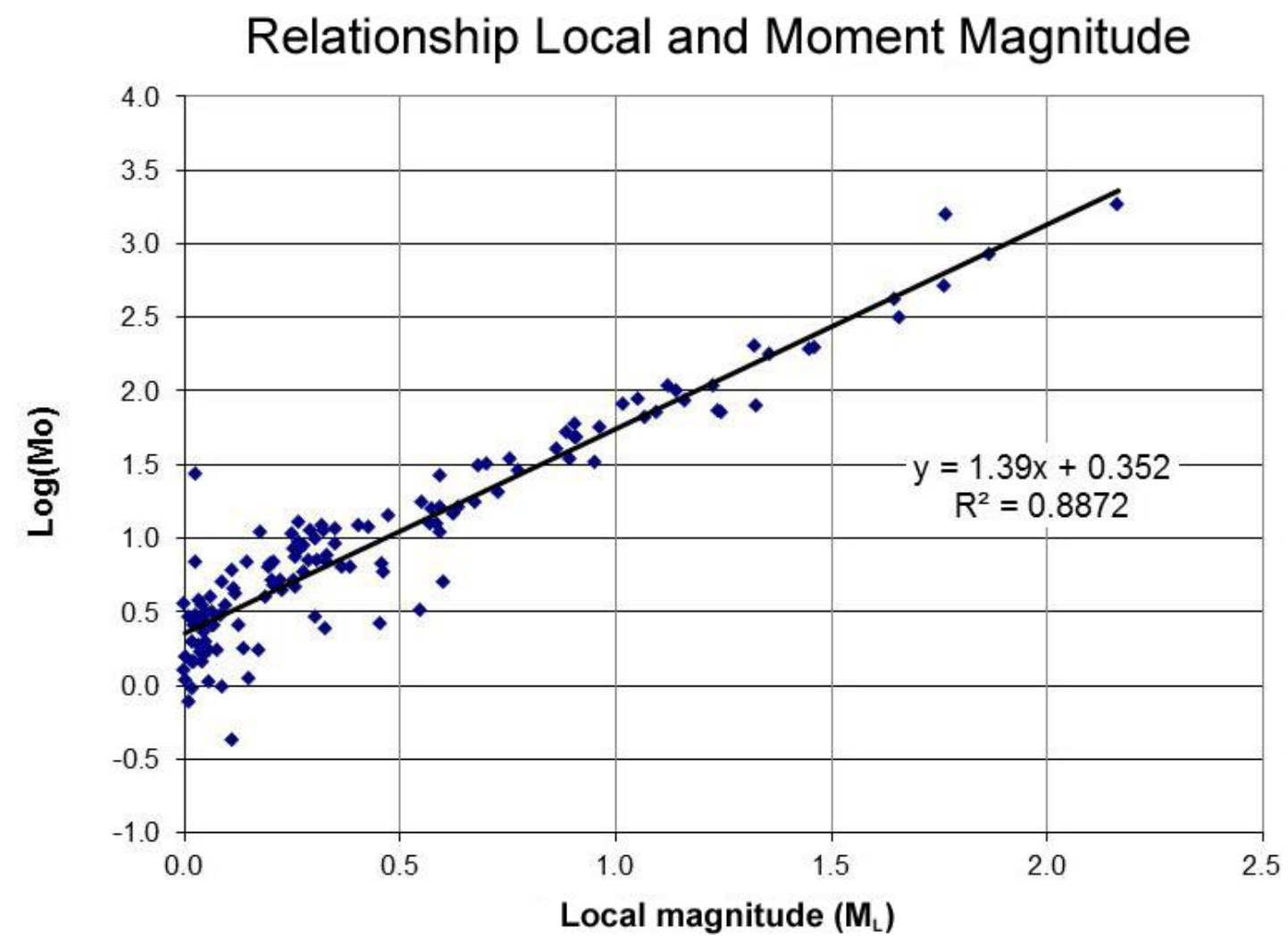

Figure 11 Relationship between local magnitude and moment magnitude

Kaiser et al. (1996) recommends that an $a$ value of 0.5 is used: this defines the slope of the linear regression line in Figure 10. It fitted the data for RWD well and was therefore applied here but should be assessed for each site if good quality data is available.

Kaiser et al. (1996) recommend design $C^{*}$ values of between 0.2 and 0.3 for stress drops of less than $2.5 \mathrm{MPa}$; for RWD the value of 0.85 was used for the initial support design as it was calculated directly from the available data and erred on the conservative side. As the majority of the sensors in the RWD seismic system are accelerometers, the accelerations had to be integrated to establish velocity. As a first pass this data was integrated using 2. $\pi . f$, where $f$ is the corner frequency; this assumes that the wave form is sinusoidal and may contribute to the higher $C^{*}$ values.

Establishing the $C^{*}$ and a values allowed the relationship between the distance from the source to the target area, the local magnitude and $p p v$ to be plotted (Figure 12), which could then be used for ground support and reinforcement design. 


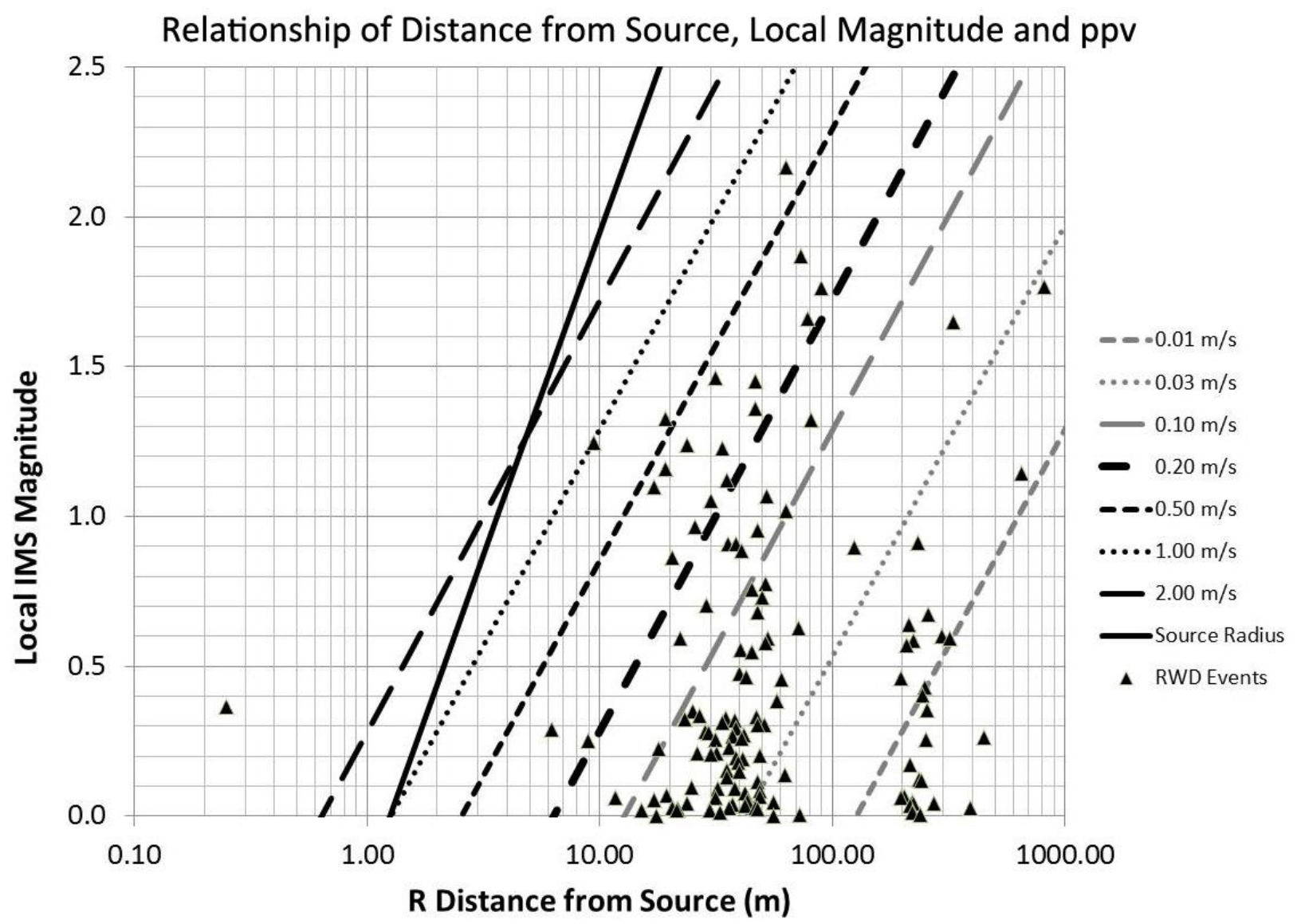

Figure 12 Relationship of distance from source, local magnitude and ppv for RWD data

\section{Strainburst}

During development at RWD there was no evidence of ejection from strainbursts on the EL and strainbursts that did occur were relatively minor, usually occurring in recently excavated ground which had yet to be supported.

\subsection{Self-Initiated strainburst}

Self-initiating strainbursts were assessed using the methods outlined in Kaiser et al. (1996) and Scott et al. (2008). The strainburst depth was limited to the depth of baggage plus 0.15 times the radius of the circle inscribed on the opening. The method outlined in Obert and Duvall (1967), Jaeger and Cook (1969), and Kaiser (1993) was used to estimate the energy released. This assumes that the tunnel is circular and is in a uniform stress field, the energy released is defined by Equation 3.

$$
E s=\frac{\pi\left(S^{2}\right)}{2 G}\left\{a_{2}^{2}-a_{1}^{2}\right\}
$$

Where:

$E_{\mathrm{s}} \quad=\quad$ the energy released $(\mathrm{J})$.

$S=$ the stress $(\mathrm{Pa})$.

$G \quad=\quad$ the rock mass Shear Modulus $(\mathrm{Pa})$.

$a_{2}=$ the radius of the opening after strainburst $(\mathrm{m})$.

$a_{1}=$ the radius of the opening before the strainburst $(\mathrm{m})$. 
The results are shown in Table 3 and assume that only 10\% of the energy released results in the loading of the support system with the majority of the energy being used in breaking the rock mass. Also assessed in Table 1 is the bulking or deformation caused by the increase in volume. The volume increase assumes a rock mass strain of $5 \%$.

Table 3 Strainburst demand

\begin{tabular}{ccccccc}
\hline $\begin{array}{c}\text { Depth } \\
\text { Baggage } \\
(\mathbf{m})\end{array}$ & $\begin{array}{c}\text { Depth } \\
\text { Strainburst } \\
(\mathbf{m})\end{array}$ & $\begin{array}{c}\text { Total } \\
\text { Depth } \\
(\mathbf{m})\end{array}$ & $\begin{array}{c}\text { Deformation } \\
\text { due to } \\
\text { Strainburst } \\
(\mathbf{m m})\end{array}$ & $\begin{array}{c}\text { Total } \\
\text { Deformation } \\
(\mathbf{m m})\end{array}$ & $\begin{array}{c}\text { Energy } \\
\text { Released } \\
\left(\mathbf{k J} / \mathbf{m}^{2}\right)\end{array}$ & $\begin{array}{c}\text { Energy } \\
\text { Required of } \\
\text { Support at FoS } \\
\text { of } \mathbf{1 . 6}\left(\mathbf{k J} / \mathbf{m}^{2}\right)\end{array}$ \\
\hline 0.97 & 0.5 & 1.47 & 25 & 74 & 5.7 & 9.1 \\
\hline
\end{tabular}

\subsection{Strainburst initiated due to a remote seismic event}

This assessment also followed the method described in Kaiser et al. (1996), Scott et al. (2008) and Fuller (2010). The maximum stress $\left(\sigma_{\max }\right)$ was calculated using Equation 4.

$$
\sigma_{\text {max }}=\frac{\sigma_{c}}{1.34}\left\{\frac{d_{f \sqrt{2}}}{w}+0.57\right\}
$$

Where:

$\sigma_{\mathrm{c}} \quad=\quad$ the intact rock uniaxial compressive strength (UCS) (MPa).

$d_{\mathrm{f}} \quad=\quad$ the depth of failure.

$w \quad=\quad$ the width of the drive.

The increase of stress due a seismic event was calculated from Equation 5.

$$
\Delta \sigma=n c_{s} \rho p p v
$$

Where $\mathrm{n}$ is a factor which depends on the incidence angle of the dynamic wave and can range from 0 to 4 . It was assumed to be 4 for this analysis.

Where:

$c_{\mathrm{s}}=$ the shear wave velocity $(\mathrm{m} / \mathrm{s})$.

$\rho \quad=\quad$ the rock mass density $\left(\mathrm{kg} / \mathrm{m}^{3}\right)$.

ppv $=$ the peak particle velocity $(\mathrm{m} / \mathrm{s})$.

The dynamic depth of failure resulting from the increase in $\sigma_{\max }$ due to the additional stress $(\Delta \sigma)$ from the incoming wave was estimated using Equation 6.

$$
d_{f}=\frac{w}{\sqrt{2}}\left\{1.34\left(\frac{\sigma_{\max }}{\sigma_{c}}\right)-0.57\right\}
$$

The increase in the depth of failure was used to calculate the volume of failed material and the seismic energy released was calculated using Equation 3 and the results are shown in Table 4. Again it was assumed that only $10 \%$ of the energy released would be transferred to the ground support system.

Table 4 Results of assessment of strainburst due to remote seismic event

\begin{tabular}{cccccc}
\hline $\begin{array}{c}\text { Depth Static } \\
\text { Failure }(\mathbf{m})\end{array}$ & $\begin{array}{c}\text { Depth } \\
\text { Dynamic } \\
\text { Failure }(\mathrm{m})\end{array}$ & $\begin{array}{c}\text { Deformation } \\
\text { Due to } \\
\text { Increase in } \\
\text { Volume }(\mathbf{m m})\end{array}$ & $\begin{array}{c}\text { Total } \\
\text { Deformation } \\
(\mathbf{m m})\end{array}$ & $\begin{array}{c}\text { Energy } \\
\text { Released } \\
\left(\mathbf{k J} / \mathbf{m}^{2}\right)\end{array}$ & $\begin{array}{c}\text { Energy } \\
\text { Required of } \\
\text { Support at FoS } \\
\text { of } \mathbf{1 . 6}\left(\mathbf{k J} / \mathbf{m}^{2}\right)\end{array}$ \\
\hline 1.0 & 1.8 & 38 & 88 & 12.0 & 19.3 \\
\hline
\end{tabular}


The forecasted depth of failure using the RWD stress field and Equation 6 gives depths of failure that are significantly higher than the observed depths of failure underground. By back calculating the initial $\sigma_{\max }$ to the depths of failure observed underground, the method gives results that are more realistic and correspond with support and reinforcement performance at RWD.

\section{Shakedown failure due to a remote seismic event}

This section follows the process of Kaiser et al. (1996), Coffey Mining Pty Ltd (2008), Sharrock (2009) and Fuller (2010). From the GR Plot in Figure 4, the maximum magnitude event was assessed to be $2.5 \mathrm{M}$ and it was considered that this event could occur within $20 \mathrm{~m}$ of the extraction level. This results in a ppv of $3.5 \mathrm{~m} / \mathrm{s}$ at the EL from an event of this size at this distance.

A shakedown failure may occur when a remote seismic event triggers a rockfall. The energy from the event accelerates and displaces the rock mass which, if it is close to failure or the acceleration due to the event being high, results in a fall of ground.

To assess the potential for this to occur two strength factors are provided by Kaiser et al. (1996). Equation 7 is a force balance equation to assess the strength factor (SF) required to prevent the initiation or triggering of a failure Equation 8 is an energy balance equation that assesses the SF needed for the ground support system to survive a triggered event and prevent a rockfall or collapse.

$$
\begin{gathered}
S F_{\text {Trigger }}=\frac{1}{m_{d}}\left[\left(\frac{2 \pi f}{g} p p v\right)+1\right] \\
S F_{\text {Survival }}=\frac{1}{m_{d}}\left[\left((n . p p v)^{2} \frac{1}{2 g d_{u l t}}\right)+1\right]
\end{gathered}
$$

Where:

$$
\begin{array}{ll}
m_{d} & =\text { the dynamic strength multiplier assumed to be } 1.25 . \\
f & =\text { the frequency of the incoming seismic wave }(\mathrm{Hz}) . \\
p p v & =\text { the peak particle velocity }(\mathrm{m} / \mathrm{s}) . \\
g & =\text { the acceleration due to gravity }\left(\mathrm{m} / \mathrm{s}^{2}\right) . \\
n & =\text { the ejection velocity ratio }\left(v_{e} / p p v\right) \text { assumed to be } 1 \text { where } v_{e} \text { is the ejection velocity. } \\
d_{u l t} & =\quad \text { the ultimate displacement capacity of the ground support system }(\mathrm{m}) .
\end{array}
$$

To apply these equations appropriately it is useful to understand their origin. Equation 7 is a force balance equation which ignoring any capacity provided by the rock mass and assuming a case where the potential failure is from the backs of the excavation can be expressed simply as:

$$
\text { Dynamic Support Capacity }=m g+m a
$$

Where $m$ is the mass of the rock to be supported $(\mathrm{kg}), g$ is the acceleration due to gravity $\left(\mathrm{m} / \mathrm{s}^{2}\right)$ and $a$ is the acceleration due to the remote seismic event $\left(\mathrm{m} / \mathrm{s}^{2}\right)$.

Rearranging this to place the dynamic demand component on the left side of the equation gives:

$$
\begin{aligned}
m a & =\text { Dynamic Support Force Capacity }-m g \\
& =\mathrm{m}_{\mathrm{d}} \text {.Static Support Force Capacity }-\mathrm{mg}
\end{aligned}
$$

Converting the incoming acceleration to velocity by multiplying by $2 . \pi . f$ and dividing across by the mass gives:

$$
2 \pi f p p v=\frac{m d \text { Static Support Force Capacity }}{m}-g
$$

Where $f$ is the frequency of incoming seismic wave which is assumed to be sinusoidal. 
Multiplying the first term on the right side by $\mathrm{g} / \mathrm{g}$ allows the static support force capacity to be transferred to a dimensionless static strength factor (SF) or safety factor.

$$
2 \pi f v=\frac{m d(\text { Static Support Force Capacity) } g}{m g}-g
$$

Dividing across by $2 . \pi . f$ gives us the equation in terms of the velocity required to trigger a rockfall in the backs:

$$
p p v=\frac{g}{2 \pi f}\left(\mathrm{~m}_{d} S F-1\right)
$$

This can be rearranged so it is expressed in terms of a triggering strength factor:

$$
S F_{\text {Trigger }}=\frac{1}{m_{d}}\left[\left(\frac{2 \pi f}{g} p p v\right)+1\right]
$$

Equation 8 is an energy balance equation ignoring any contribution of the rock mass to energy absorption and assuming a case where the potential failure is from the backs of the excavation, it can be expressed simply in terms of kinetic and potential energy as;

$$
\text { Support Energy Capacity }=\frac{1}{2} m v^{2}+m g h
$$

Rearranging this equation so the dynamic component is on the left side gives:

$$
\frac{1}{2} m v^{2}=\text { Support Energy Capacity }-m g h
$$

The support energy capacity is equal to the support force capacity multiplied by the displacement available to the support system, in this case expressed as $d_{u l t}$ as this is the allowable displacement for the system. Since $d_{\text {ult }}$ is the distance travelled by the bursting mass from the back, it can replace $h$ in the potential energy. This allows the equation to be re-written as:

$$
\frac{1}{2} m v^{2}=\text { Support Force Capacity. } d_{u l t}-m g d_{u l t}
$$

Multiplying across by two, dividing across by the mass and multiplying the first term on the right side by $\mathrm{g} / \mathrm{g}$, allows the equation to be expressed in terms of velocity squared and support force capacity to be converted to a dimensionless factor of safety (FoS) or strength factor and $m d$ is introduced to account for the effects of loading the support dynamically:

$$
v^{2}=2 m d\left(\frac{\text { Support Force Capacity }}{m g}\right) g \cdot d_{u l t}-2 g d_{u l t}
$$

Taking the square root of the right side and introducing the term $n$, an ejection velocity ratio allows us to derive the $p p v$ as:

$$
p p v=\frac{1}{n} \sqrt{2 g d_{u l t}\left(m_{d} S F-1\right)}
$$

This equation can be rearranged so it is expressed in terms of a survival strength factor:

$$
S F_{\text {Survival }}=\frac{1}{m_{d}}\left[\left(\left((n . p p v)^{2}\right) \frac{1}{2 g d_{u l t}}\right)+1\right]
$$

To assess the demand from a remote seismic event the following steps were followed:

1. The static depth of failure was measured or estimated using Equation 6 and using Equation 21 to calculate the input $\sigma_{\max }$.

$$
\sigma_{\max }=3 \sigma_{1}-\sigma_{3}
$$

2. The maximum dynamic stress increment $(\Delta \sigma)$ was then calculated using Equation 5 , inputting the ppv of the incoming event from Equation 1.

3. $\sigma_{\max }$ was then recalculated from Equation 22 to include the maximum dynamic stress increment. 


$$
\sigma_{\max }=3 \sigma_{1}-\sigma_{3}+\Delta \sigma
$$

4. The dynamic depth of failure was calculated using Equation 6 inputting the $\sigma_{\max }$ calculated in the previous step.

5. These values could be used to assess the total depth of failure and the anticipated bulking of the rock mass which allows us to establish the length of ground support and the displacement capacity required of the ground support.

6. Equations 7 and 8 , the $S F_{\text {Trigger }}$ and the $S F_{\text {Survival }}$ are now calculated. The following inputs were used when calculating these strength factors, $\mathrm{m}_{\mathrm{d}}$ was assumed to be $1.25, \mathrm{n}$ was assumed to be 1.0 and $\mathrm{f}$ was assumed to be $20 \mathrm{~Hz}$. The ultimate displacement varied depending on the ground support system being used.

The results are shown in Table 5 for different magnitude events at $20 \mathrm{~m}$ distance from the excavation and in Table 6 for a $2.5 \mathrm{ML}_{\mathrm{L}}$ event at various distances from the excavation.

Table 5 Results of shakedown rockfall assessment at varying $M_{L}$ at $20 \mathrm{~m}$

\begin{tabular}{ccccccc}
\hline $\mathbf{M}_{\mathbf{L}}$ & Distance $(\mathbf{m})$ & ppv $(\mathbf{m} / \mathbf{s})$ & $\begin{array}{c}\text { Total Depth } \\
\text { Failure }(\mathbf{m})\end{array}$ & $\begin{array}{c}\text { Static Load } \\
\left(\mathbf{k N} / \mathbf{m}^{2}\right)\end{array}$ & SF Trigger & SF Survival \\
\hline 2.5 & 20 & 3.48 & 4.21 & 118 & 36.5 & 3.3 \\
2.0 & 20 & 1.56 & 2.98 & 83 & 16.8 & 1.3 \\
1.5 & 20 & 0.70 & 2.43 & 68 & 8.0 & 0.9 \\
1.0 & 20 & 0.32 & 2.18 & 61 & 4.0 & 0.8 \\
0.5 & 20 & 0.14 & 2.07 & 58 & 2.25 & 0.8 \\
0.0 & 20 & 0.06 & 2.02 & 57 & 1.45 & 0.8 \\
\hline
\end{tabular}

The results show that the ground support system would be unable to prevent the initiation or triggering of a rockfall from an event of magnitude $2.5 \mathrm{M}$ or greater at a distance of $20 \mathrm{~m}$ or less. However, if there is sufficient load and displacement capacity the ground support system should be capable of surviving an event of $2.5 \mathrm{M}$ at $20 \mathrm{~m}$.

Table 6 Results of shakedown rockfall assessment at varying distance for a 2.5 $\mathrm{M}_{\mathrm{L}}$ Event

\begin{tabular}{ccccccc}
\hline $\mathbf{M}_{\mathbf{L}}$ & $\begin{array}{c}\text { Distance } \\
(\mathbf{m})\end{array}$ & ppv $(\mathbf{m} / \mathbf{s})$ & $\begin{array}{c}\text { Total Depth } \\
\text { Failure }(\mathbf{m})\end{array}$ & $\begin{array}{c}\text { Static Load } \\
\left(\mathbf{k N} / \mathbf{m}^{\mathbf{2}}\right)\end{array}$ & SF Trigger & SF Survival \\
\hline 2.5 & 20 & 3.48 & 4.21 & 118 & 36.5 & 3.3 \\
2.5 & 30 & 2.32 & 3.46 & 97 & 24.6 & 1.9 \\
2.5 & 40 & 1.74 & 3.09 & 86 & 18.6 & 1.4 \\
2.5 & 50 & 1.39 & 2.87 & 80 & 15.1 & 1.2 \\
2.5 & 100 & 0.70 & 2.43 & 68 & 9.9 & 0.9 \\
\hline
\end{tabular}

The SF or FoS that are calculated using these formulas are the static factors of safety that are required to achieve a dynamic FoS of 1 . To increase the dynamic FoS to greater than this, a surcharge support capacity must be applied. 


\section{Defining the support and reinforcement capacity}

Three support schemes were defined for the RWD EL Drive. These were designed to cope with the variability of rock mass conditions, different zones of deformation and the effects of seismic events. These were assessed against both the static and dynamic load demands.

To be able to properly quantify the capacity of the support and reinforcement systems in static and dynamic conditions, the full load-displacement response curve must be quantified for each support and reinforcement element in the scheme. This information can be sourced from dynamic testing facilities, static testing and in situ testing. If none of these are available then the manufacturer's specifications must be used to approximate the load-displacement curve. If testing data is not available every effort should be made to collect the necessary information as soon as is practical so that the full load-displacement curve can be quantified. The testing should be done with the plates and bolts to be used in the field so that the compatibility of the entire system can be assured. Figure 13 shows the load response curve for a full system test on a R27 resin bolt with 0.75 and $1 \mathrm{~m}$ free lengths, from Sharrock et al. (2010). It also shows the points at which yield displacement, yield capacity, ultimate displacement and ultimate capacity were measured.

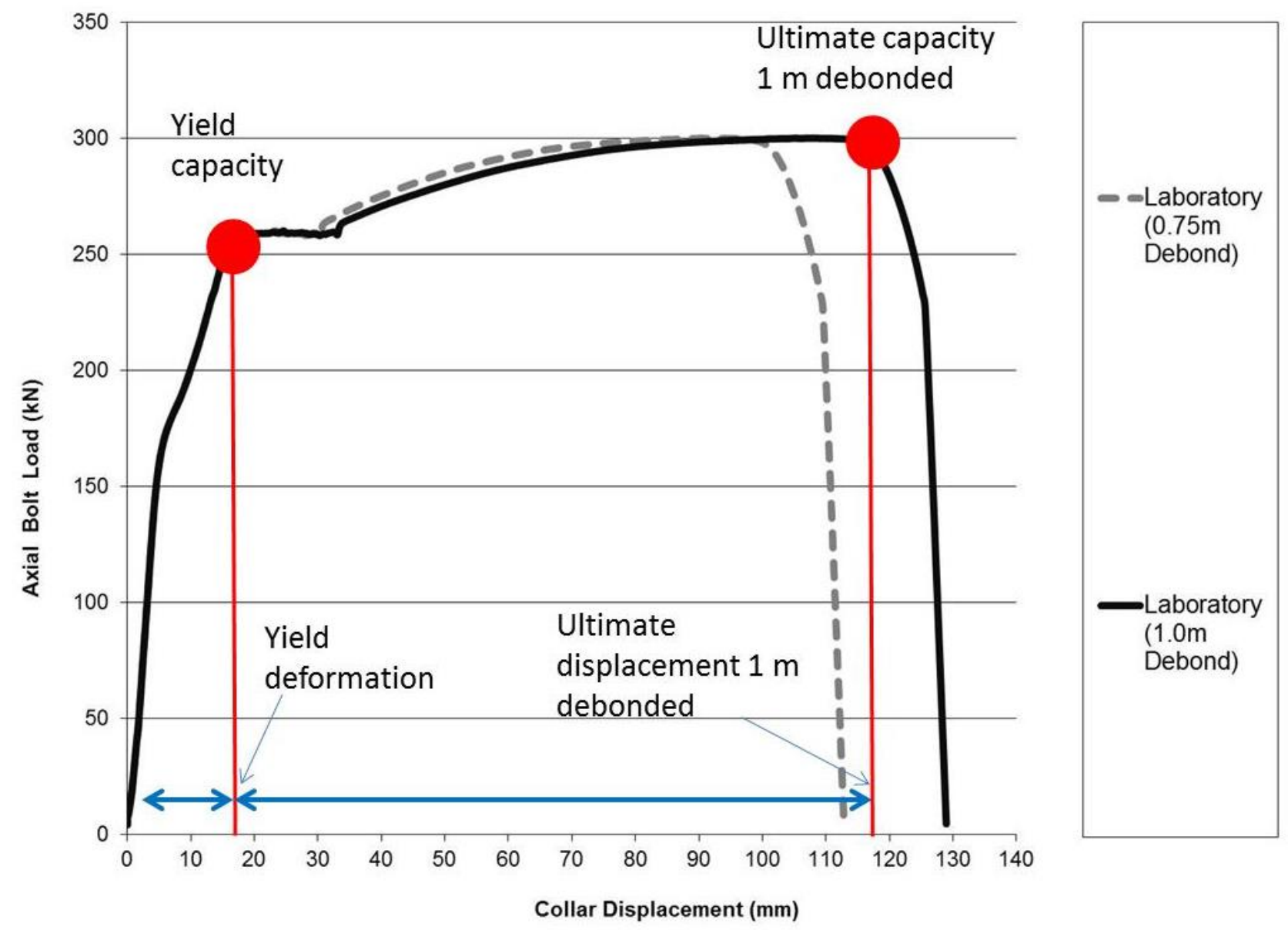

Figure 13 Static load-displacement curve for debonded R27 resin bolts

From the full load-displacement curves the yield capacity, yield deformation, ultimate capacity and ultimate deformation can be measured for reinforcement elements and shotcrete. For mesh the displacement at rupture and the load at rupture (Player et al., 2008) can be measured. These can then be used to approximate the load-displacement response of each element in the ground support system so that the relative response of each element and the total response of the system can be determined. The load-displacement curves for most bolts and shotcrete used at RWD can be approximated as bilinear curves with the first line defining the pre-yield response and the second line defining the post yield response through to ultimate failure. The load response of friction bolts can be approximated as a bilinear 
curve; it is especially important that the available embedment is quantified so the capacity can be reduced as embedment reduces. The response of mesh can be approximated with a curve defined by Equation 23.

$$
y=b^{x}
$$

Where:

$y=$ the load capacity $(\mathrm{kN})$.

$x=\quad$ the displacement $(\mathrm{m})$.

The constant $b$, is calculated from the displacement at rupture and the load capacity at rupture of the mesh, for $5.6 \mathrm{~mm}$ gauge mesh $b$ was calculated to be $1.024 \times 10^{8}$. The post yield capacity of the mesh was not accounted for in this analysis. These are all simplifications of the actual load-displacement curves but they permit the various components of the ground support system to be assessed and their relative contributions can be quantified.

For each reinforcement type a minimum anchor length was specified. If the rock mass failure depth was greater than the length of the bolt remaining below the anchor, the reinforcement's contribution to the support system was zero.

For analysis of support capacity, a spreadsheet was developed that allows the load capacity of the system to be assessed, quantifying the embedment length, load capacity, deformation capacity and energy absorption capacity available on each element in the system and summing these to assess the overall system's capacity. Ground deformation is included in this analysis, as well as the depth of failure and deformation due to rock mass strain. The time of bolt installation is accounted for by defining the depth of failure at the time of installation and the loss of deformation capacity due to pre-tensioning was also allowed for. This permits the assessment of the relative contributions of the support and reinforcement systems and when these contributions occur.

By plotting these together we can assess if the depth of failure has compromised any of the elements in the system, sum the remaining energies and the load capacities at the current deformation, assess the deformation available at different depths of failure for the various elements, and assess if these deformations are compatible and when the various elements are compromised as deformation proceeds. A plot of the indicative capacities of the various elements used in the ground support systems for RWD is shown in Figure 14.

In practice it is important to be mindful of the compatibility of the support and reinforcement systems being used. It is not uncommon to see failure of surface support leading to the unravelling of broken or loosened rock mass with the reinforcement remaining relatively undamaged when a rock burst has occurred.

The $S F_{\text {survival }}$ assumes that the load capacity is constant from the start of deformation until the ultimate deformation is reached. This is not the case for most support elements and careful selection of the load capacity is required to ensure that the results are consistent with the ground support system's capabilities. It is also important that the $d_{u l t}$ used is the maximum allowable deformation of the system.

By integrating the area under each curve the energy available can be calculated. This will be affected by the amount of rock mass deformation since the support was installed, the support load capacity and its ultimate displacement. 


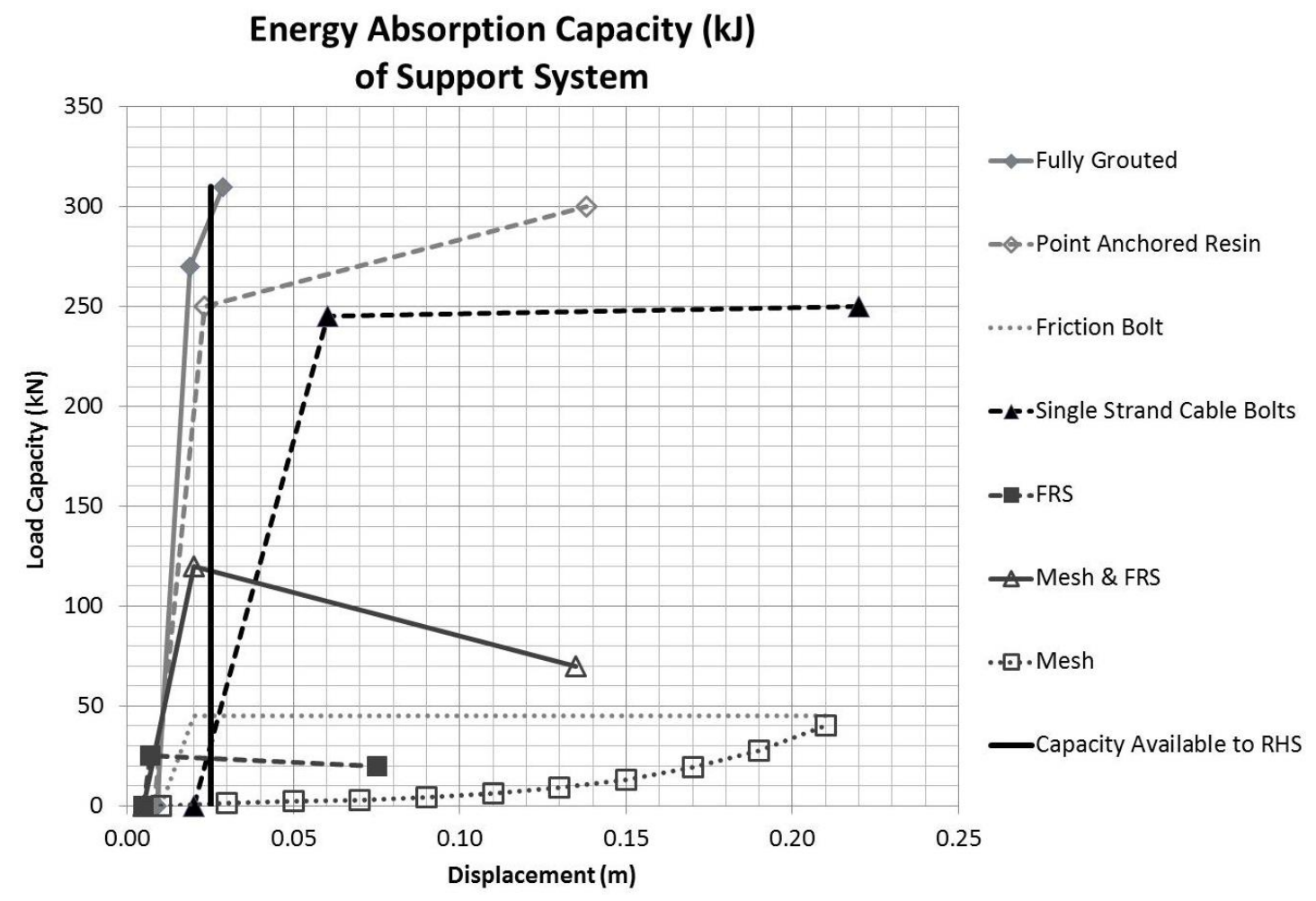

Figure 14 Indicative load-displacement curves for support and reinforcement systems used at RWD

\section{$14 \quad$ Ground support systems}

Table 7 shows the reinforcement systems used for the extraction drives at RWD. All areas were sprayed with a $50 \mathrm{~mm}$ layer of fibre reinforced shotcrete (FRS). They were then meshed using $5.6 \mathrm{~mm}$ gauge mesh before having a final layer of $50 \mathrm{~mm}$ of FRS sprayed over the mesh layer. All support was applied down to the floor.

Table 7 Ridgeway deeps EL reinforcement

\begin{tabular}{cccc}
\hline & \multicolumn{3}{c}{ System 1: Centre of Footprint } \\
Reinforcement & Bolt Length $(\mathbf{m})$ & Spacing $(\mathbf{m})$ & Description \\
\hline Resin bolt & 2.4 & $1.2 \times 1.2$ & Fully bonded R27 resin bolt \\
Cable bolt & 6.3 & $1.8 \times 1.5$ & Single bulbed strand cable \\
\hline & System 2: Abutments $\mathbf{2 0}$ m away from the Claudia Fault \\
\hline Reinforcement & Bolt Length (m) & Spacing (m) & Description \\
\hline Resin bolt & 2.4 & $1.2 \times 1.2$ & Fully bonded R27 resin bolt \\
Cable bolt & 6.3 & $1.8 \times 1.2$ & Twin bulbed strand cable \\
\hline & System 3: Southern Abutment within $\mathbf{2 0}$ m of Claudia Fault \\
\hline Reinforcement & Bolt Length (m) & Spacing (m) & Description \\
\hline Resin bolt & 2.4 & $1.2 \times 1.2$ & Resin bolt 1 m free length \\
Cable bolt & 8.3 & $1.5 \times 1.5$ & Dynamic cables 4.5 m debonded length \\
\hline
\end{tabular}


Table 8 gives the demand on the ground support systems and the required static load capacity of the support system. The static depth of failure was calculated to be $1 \mathrm{~m}$ prior to the event using Equation 6 . The ground support spreadsheet was used to estimate the load capacities and the remaining displacements were also calculated so that $d_{\text {ult }}$ could be entered into the $S F_{\text {survival }}$ calculation.

Table 8 Required ground support capacity (static depth of failure $=1 \mathrm{~m}$ )

\begin{tabular}{cccccc}
\hline $\begin{array}{c}\text { Local } \\
\text { Magnitude }\end{array}$ & Distance $(\mathbf{m})$ & $\begin{array}{c}\text { Static Load } \\
\left(\mathbf{k N} / \mathbf{m}^{2}\right)\end{array}$ & SF Survival & $\begin{array}{c}\text { Required Load } \\
\text { Capacity } \\
\left(\mathbf{k N} / \mathbf{m}^{\mathbf{2}}\right)\end{array}$ & $\begin{array}{c}\text { Surcharge of 1.5 } \\
\text { for Dynamic } \\
\text { Loading }\end{array}$ \\
\hline 2.5 & 20 & 118 & 3.3 & 389 & 584 \\
2.5 & 30 & 97 & 1.9 & 184 & 276 \\
2.5 & 40 & 86 & 1.4 & 120 & 180 \\
2.5 & 50 & 80 & 1.2 & 96 & 144 \\
2.5 & 100 & 68 & 0.9 & 61 & 92 \\
\hline
\end{tabular}

The static load capacities calculated for the three support systems outlined in Table 7 are shown in Table 9. The results indicate that System 1 is suitable for use between 40 and $50 \mathrm{~m}$ away from the likely source of a $2.5 \mathrm{M} L$ event. System 2 is adequate support at a distance of just outside $30 \mathrm{~m}$ from the event source and System 3 at just over $20 \mathrm{~m}$.

Table 9 Ground support capacities (static depth of failure $=1 \mathrm{~m}$ )

\begin{tabular}{ccccc}
\hline $\begin{array}{c}\text { Ground Support } \\
\text { System }\end{array}$ & $\begin{array}{c}\text { Energy Absorption } \\
\text { Capacity (kJ) }\end{array}$ & $\begin{array}{c}\text { Static Capacity } \\
\left(\mathbf{k N / \mathbf { m } ^ { 2 } )}\right.\end{array}$ & $\begin{array}{c}\text { Residual } \\
\text { Displacement } \mathbf{( m )}\end{array}$ & $\begin{array}{c}\text { Survival } \\
\text { Distance }(\mathbf{m})\end{array}$ \\
\hline System 1 & 25 & 578 & 0.200 & 20 \\
System 2 & 44 & 272 & 0.175 & 32 \\
System 3 & 78 & 157 & 0.175 & $40-50$ \\
\hline
\end{tabular}

The energy absorption capacities are more than adequate to cope with the energy from the strainbursting calculated earlier and the static load capacities are well in excess of the likely static loads from wedges and ground deformation. However, in the near-field it is possible to have ppvs greater than predicted by the method used here and the maximum practical support limit (MPSL) (Kaiser et al., 1996) may be reached. In this situation other strategies for mining must be considered.

\section{Monitoring the performance of the ground support systems}

At the outset of RWD a concerted effort was made to monitor the mine. This included instrumenting the EL using closure pins, extensometers, SMART cable bolts, observation holes and photogrammetry (Lowther et al., 2010). Results have been used to assess the depth of damage and the deformations that have occurred. In conjunction with the monitoring, damage mapping has been completed every month since the beginning of undercutting which has allowed the location and severity of damage to be tracked as mining has progressed Lowther et al. (2010). This forms an important input into numerical modelling and the calibration of these models.

Seismicity has been reassessed as more data has become available, with any damage from events around the mine being back-analysed and the key parameters $a, C^{*}$ and velocity being calibrated with the larger database (Mobilio, 2012). Work has also progressed in understanding the source mechanisms of seismicity at RWD (Sileny et al., 2013). 
As more information is collected and assessed it is used to optimise the future ground support and reinforcement design and implementation at RWD and Cadia East.

\section{Conclusions}

The ground support systems described were successfully implemented at RWD EL allowing production to ramp up to design capacity whilst providing safe development and access to the draw points. On the EL, the reinforcement and support has been damaged principally by deformations with only minor damage resulting from seismic activity. Despite this damage the extraction drives have maintained their functionality.

By applying this methodology, the geotechnical engineers have been able to design the ground support systems in a systematic and practical manner. Only by applying it have they been able to understand the complexity of the method and how to assess the key parameters that would influence the demand and the capacity of the system. This will enable them to adapt the methodology and apply it in the future to optimise the support designs.

The methodology used was peer reviewed by internal and external independent reviewers and was deemed to be appropriate for the conditions at the mine. This gave management and the operations team confidence to apply the resulting designs.

It is important that work continues to better understand and define the ground conditions and response of the support and reinforcement systems at RWD, through damage mapping, monitoring and the analysis of seismic data. This enables us to better quantify the future damage and to calibrate numerical models. The back-analysis of damaging events and seismicity is improving how we use this data and allowing us to better define the key variables for input into future design. All of this work is allowing us to improve the ground support design and its application in future mining endeavours.

The design engineer must always be mindful that ground support and reinforcement is one element in the overall ground control management plan that is in place to ensure that excavations are safe and retain their functionality. The ground control management plan should start with the choice of mining method, the planning of the mine layout and the sequencing of development and production. It needs to include the standards and procedures that ensure safe work practices, the utilisation of appropriate equipment to the task and the training of all members of the workforce for their specific roles. It is important that ground awareness training is included in the training modules to ensure personnel are cognisant of the risks and know how to deal with them appropriately. In seismically active mines, the standards and procedures should include measures such as the restriction of personnel from areas of potential hazard via spatial and temporal exclusion zones, and the removal of personnel from proximity to hazards by the use of equipment. Only by having a holistic plan of which ground support and reinforcement design and implementation are an integral part will the ground support system and the mine achieve leading practice and success.

\section{Acknowledgements}

The author thanks Newcrest Mining Ltd for the support and permission to publish this paper. The paper is a summary of work undertaken at Ridgeway Deeps since 2006 through to the present by the geotechnical team: Glenn Sharrock, Geoff Capes, Robert Lowther, Phil Earl, lan Brunton and James Lett. The author is also grateful to Glenn Sharrock and Peter Fuller for their comments, explanations and reviews during the course of writing the paper.

\section{References}

Beck, D.A., Sharrock, G. and Capes., G. (2011) A coupled DFE-Newtonian Cellular Automata scheme for simulation of cave initiation, propagation and induced seismicity, in Proceedings 45th US Rock Mechanics Symposium, G.S. Esterhuizen, A.N. Tutuncu and A.T. lannacchione (eds), 26-29 June 2011, San Francisco, USA, American Rock Mechanics Association, Alexandria. 
Beck Arndt Engineering (2009) Ridgeway Deeps Project Numerical assessment of M9 Mining Sequence September 2009, Newcrest Mining Ltd, unpublished document.

Brown, E.T. (2003) Block caving geomechanics, Julius Kruttschnitt Minerals Research Centre, University of Queensland, Brisbane, 2nd edition.

Coffey Mining Pty Ltd (2008) Ground Support Review Ridgeway Deeps MINENHILL00118AB_V01, Newcrest Mining Ltd, unpublished document.

Ferguson, J. (2009) Ridgeway Deeps Structural Interpretation, Newcrest Mining Ltd, unpublished document.

Finn, D.J. (2007) Ridgeway Deeps Monitoring Proposal, Newcrest Mining Ltd, unpublished document.

Fuller, P. (2010) Ground Support Performance and Selection in Seismically Active Mines, in Proceedings Second Australasian Ground Control in Mining Conference, P. Hagan and S. Saydam (eds), 23-24 November 2010, Sydney, Australia, The Australasian Institute of Mining and Metallurgy, Melbourne.

Gutenberg, B. and Richter, C.F. (1956) Magnitude and energy of earthquakes, Annali di Geofisica, Rome, Vol. 9, pp. 1-15.

Hall, J. (2006) Ridgeway Deeps Hydrogeology Assessment Letter Report, Aquaterra, unpublished document.

Jaeger, J.C. and Cook, N.G.W (1969) Fundamentals of Rock Mechanics, Methuen \& Co., London, 513 p.

Jeffery, R. (2007) Hydraulic Fracturing Trial - Ridgeway Deeps Preconditioning, CSIRO Petroleum Confidential Report, No. 07-011, unpublished.

Kaiser, P.K., McCreath, D.R. and Tannant, D.D. (1996) Canadian Rockburst Support Handbook, Geomechanics Research Centre, Sudbury.

Kaiser, P.K. (1993) Support of tunnels in burst prone ground-Toward a rational design methodology, in Proceedings Third International Symposium on Rockbursts and Seismicity in Mines, P. Young (ed), 16-18 August 1993, Kingston, Canada, Balkema, Rotterdam, pp. 13-27.

Lett, J.L. and Capes, G.W. (2012) Characterisation of Caving and Subsidence for operational enhancements at the Newcrest Ridgeway Gold Mine, in Proceedings 6th International Conference \& Exhibition on Mass Mining (Massmin 2012), 10-14 June 2012, Sudbury, Canada.

Lett, J.L. (2009a) RWD Geotechnical Block Model, Newcrest Mining Ltd, unpublished document.

Lett, J.L. (2009b) 2009 Ridgeway Rock Strength Database Memorandum, Newcrest Mining Ltd, unpublished document.

Lowther, R.J., Capes, G.W. and Sharrock, G.B. (2010) A deformation monitoring plan for extraction level drives at Ridgeway Deeps block cave mine, in Proceedings 2nd International Symposium on Block and Sublevel Caving (Caving 2010), Y. Potvin (ed), 20-22 April 2010, Perth, Australia, Australian Centre for Geomechanics, Perth, pp. 93-106.

Mobilio, B. (2012) The Influence of Seismicity on Underground Excavations, CIVE1167 Investigation Project, School of Civil, Environmental and Chemical Engineering, RMIT University.

Newcrest (2011) Technical Report on the Cadia Valley Operations Property in New South Wales Australia, Newcrest Mining Limited, viewed 28 January 2013, http://www.newcrest.com.au/media/resource_reserves/Technical\%20Reports/FINAL_(a4)_ Technical_Report_Cadia_Valley_Property_December_31_2011.pdf.

Obert, L. and Duvall, W.I. (1967) Rock Mechanics and the Design of Structures in Rock, John Wiley and Sons, New York, $650 \mathrm{p}$.

Player, J.R., Morton, E.C., Thompson, A.G. and Villaescusa, E. (2008) Static and Dynamic testing of Steel Wire Mesh for Mining Applications of Rock Surface Support, in Proceedings 6th International Symposium On Ground Support in Mining and Civil Engineering Construction, 31 March-3 April 2008, Cape Town, South Africa, The South African Institute of Mining and Metallurgy, Cape Town, pp. 693-706.

Scott, C., Penney, A.R. and Fuller, P. (2008) Competing Factors in Support Selection for the West Zone of the Beaconsfield Gold Mine Tasmania, in Proceedings Narrow Vein Mining 2008 Conference, S. Dominy (ed), 14-15 October 2008, Ballarat, Victoria, Australasian Institute of Mining and Metallurgy, Melbourne.

Sharrock, G.B., Beck, D. and Capes, G.W. (2012) Applying coupled Newtonian Cellular Automata - Discontinum Finite Element models to simulate propagation of Ridgeway Deeps Block Cave, in Proceedings 6th International Conference and Exhibition on Mass Mining (MassMin 2012), 10-14 June 2012, Sudbury, Canada.

Sharrock, G.B. (2009) Ridgeway Deeps Block Cave Extraction Level Ground Support and Reinforcement, Newcrest Mining Ltd, unpublished document.

Sharrock, G.B., Capes, G., Fuller, P., Kerr, G. and Penney, A. (2010) Laboratory and Field Tests on Point Anchored Resin Bolts at the Ridgeway Deeps Block Cave, in Proceedings Second Australasian Ground Control in Mining Conference, P. Hagan and S. Saydam (eds), 23-24 November 2010, Sydney, Australia, The Australasian Institute of Mining and Metallurgy, Melbourne, pp. 261-268.

Sileny, J., Lotter, E.C. and Capes, G. (2013) Mining induced seismicity: moment tensor vs. shear-tensile/ implosion model. Case study of Ridgeway, E. Australia gold mine, in Proceedings 8th International Symposium on Rockbursts and Seismicity in Mines, 1-7 September 2013, Russia, St. Petersburg-Moscow.

Smart, G. and O'Sullivan, T. (2006) Local scale estimation of sublevel cave stocks - is it possible? A case study in reconciliation of metal production - Ridgeway Mine, New South Wales, in Proceedings Sixth International Mining Geology Conference, 21-23 August 2006, Darwin, Australia, Australian Institute of Mining and Metallurgy, Melbourne, pp. 323-333. 